\title{
Two-Level Credit Financing for Noninstantaneous Deterioration Items in a Supply Chain with Downstream Credit-Linked Demand
}

\author{
Yong He and Hongfu Huang \\ Institute of Systems Engineering, School of Economics and Management, Southeast University, Nanjing 210096, China \\ Correspondence should be addressed to Yong He; heyong@126.com
}

Received 22 May 2013; Revised 30 July 2013; Accepted 31 July 2013

Academic Editor: Zhigang Jiang

Copyright (c) 2013 Y. He and H. Huang. This is an open access article distributed under the Creative Commons Attribution License, which permits unrestricted use, distribution, and reproduction in any medium, provided the original work is properly cited.

\begin{abstract}
Trade credit financing is a useful tool in business today, which can be characterized as the agreement between supply chain members such as permissible delay in payments. In this study, we assume that the items have the property of noninstantaneous deterioration and the demand is a function of downstream credit. Then, an EOQ model for noninstantaneous deterioration is built based on the two-level financing policy. The purpose of this paper is to maximize the total average profit by determine the optimal downstream credit period, the optimal replenishment cycle length, and the optimal ordering quantity per cycle. Useful theorems are proposed to characterize the method of obtaining the optimal solutions. Based on the theorems, an algorithm is designed, and numerical tests and sensitive analysis are provided. Lastly, according to the sensitive analysis, managerial insights are proposed.
\end{abstract}

\section{Introduction}

Deteriorating products are prevalent in our daily life. According to Shah et al. [1], deterioration is defined as decay, change, or spoilage through which the items are not the same as its initial conditions. There are two categories of deteriorating items. The first one is about the items that become decayed, damaged, or expired through time, such as meat, vegetables, fruits, and medicine. The second category is about the items that lose part or total value through time, such as computer chips, mobile phones, and seasonal products. Both of the two kinds of items have short life cycle. After a period of existence in the market, the items lose the original economic value due to consumer preference, product quality or other reasons.

Early research on deteriorating items can be dated back to 1963. An EOQ model with exponentially decaying inventory was initially proposed by Ghare and Schrader [2]. In their study, they show that the inventory level is not only related to the market demand but also to the deteriorating rate, which is a negative exponential function of time. They proposed the deteriorating items inventory model in which $d I(t) / d t+$ $\theta I(t)=-f(t)$. In the function, $f(t)$ is the demand rate at time $t, I(t)$ stands for the inventory level and, $\theta$ refers to the deteriorating rate. Based on the assumption of Ghare and Schrader [2], many researchers extended the model by making different assumptions for the deteriorating rate, the demand rate, or shortages allowed, such as Covert and Philip [3], Philip [4], Y. He and J. He [5], He et al. [6], Yang et al. [7], and He and Wang [8]. They all proposed instructive conclusions for real practice. Recently, Goyal and Giri [9] and $\mathrm{Li}$ et al. [10] made excellent and detailed review of deteriorating inventory works.

In the above mentioned works, most researchers assume that the deterioration of the products in inventory starts from the arrival in stock. But, in practice, some kinds of products may maintain the original condition for a short time, which means during that time, there is no deterioration. For example, the stock of the firsthand vegetables or fruits has a high quality at the beginning time, in which there is no spoilage. Afterward, the stock starts to perish and induce the deterioration cost. Under this circumstance, it is obvious that the assumption that the deterioration starts from the beginning can make the retailer overestimate the inventory cost, which leads to uneconomical inventory policies. This phenomenon is first proposed by Wu et al. [11] as "noninstantaneous deterioration". They proposed the optimal 
replenishment policy of an EOQ model when the demand is inventory level dependent and can be partially backlogged. Based on this assumption, there were several interesting and relevant works such as Ouyang et al. [12, 13], Sugapriya and Jeyaraman [14], Chung [15], Yang et al. [16], Wu et al. [17], Geetha and Uthayakumar [18], Singh et al. [19], Chang and Lin [20], Chang et al. [21], Maihami and Nakhai Kamalabadi [22], and Shah et al. [1].

Furthermore, different from traditional EOQ models, in which payment should be made to the supplier after the retailer receiving the stock, many researches are focusing on the application of trade credit financing tools to improve profits or reduce cost of the supply chain. Actually, it is more practical that the supplier/retailer allows for a fixed period to settle the payment without penalty for its retailer/customer to induce its demand rate or reduce on hand inventory. This permissible delay in payment can reduce the capital investment of stock amount, thus reducing the holding cost of inventory. Besides, during the credit period, the retailer can gain interest profit of his sales revenue by the investing or banking business. Over the years, research on this part is prevalent in many works. Goyal [23] was the first to study the EOQ model with permissible delay in payment. Then Aggarwal and Jaggi [24], Jamal et al. [25], Chang and Dye [26], and Teng [27] extended Goyal's [23] model for deteriorating items, allow for shortages, and so forth. A lot of useful and interesting managerial insights were proposed in their papers. More research on this part can be found in Chung et al. [28], Teng et al. [29], Jaber and Osman [30], and Chung and Liao [31].

The above mentioned works are all assumed one-level credit financing, but sometimes this assumption is unrealistic in real business. For car companies, like TATA (India) and TOYOTA (Japan), they not only delay the payment of the purchasing cost until the end of the credit period to their suppliers, but also provide a credit period to their customers. This kind of business style is called two-echelon (two-level or two-part) credit financing. Huang [32] first proposed an EOQ model with two-level credit financing, and the retailer's credit period is longer than the customer's. Till now, researches on two-level financing can be seen in Ho et al. [33], Liao [34], Thangam and Uthayakumar [35], Chen and Kang [36], Min et al. [37], Ho [38], Urban [39], and Chung and CardenasBarron [40].

Although the credit financing problems for EOQ or EPQ models have been studied by many researchers, in most works, it is assumed that the credit period offered by the supplier/retailer to the retailer/customer is a constant parameter. Actually, in real business, supplier/retailer can decide the credit period by himself to minimize inventory cost or maximize total profit. Su et al. [41] studied the EOQ problem of a two-echelon supply chain under two-echelon trade credit financing, where the demand rate is assumed to be dependent on credit period offered by retailer to the customers. The demand rate is an exponential function of the credit period. The similar assumption can be seen in Ho [38]. Besides, Jaggi et al. [42] made a detailed explanation for the property of the credit-lined demand. They show that demand function for any credit period can be represented as the differential equation: $D(N+1)-D(N)=r(S-$ $D(N)$ ) where $S$ is the maximum demand, and $N$ is the credit period. Thangam and Uthayakumar [35] then proposed a more general continuous differential equation of the demand function based on Jaggi et al. [42] and extended their model to deteriorating items.

These effects of the situations imposes us to establish an EOQ model for noninstantaneous deteriorating items with credit-linked demand under two-echelon financing policy, which can be treated as a general framework for several papers such as Ouyang et al. [12] and Jaggi et al. [42]. There are several useful theorems proposed to illustrate the optimal solution for the model in different conditions. Here we take into account the following factors: (1) noninstantaneous deterioration items; (2) two-level credit financing is considered; (3) credit-linked demand rate; (4) the credit period offered by the supplier is not necessarily shorter than that offered by the retailer to the customer.

The remainder of this paper is organized as follows. In Section 2, assumptions and notations are described in detail. In Section 3, the EOQ model for noninstantaneous deterioration items under two-level credit financing is made. In Section 4, solutions for the model are proposed and useful theorems are presented. In Section 5, two special cases are discussed. In Section 6, numerical examples and sensitive analysis are made, and managerial insights are proposed. Conclusions and future research are given in Section 7.

\section{Notations and Assumptions}

The following notations and assumptions are adopted throughout this paper.

(1) The annual demand rate for the item, $D(N)$, which is sensitive to the credit offered by the retailer to customers and is a marginally increasing function w.r.t. $N . N$, is an integer $(N=1,2,3, \ldots)$ and a decision variable throughout this paper. $D(N)$ and $D$ can be used interchangeably in this paper.

(2) Replenishment rate is infinite.

(3) Shortage is not allowed.

(4) The product life (time to deterioration) has a probability density function $f(t)=\theta e^{-\theta(t-\gamma)}$ for $t>\gamma$, where $\gamma$ is the length of time in which the product has no deterioration and $\theta$ is a parameter. The cumulative distribution function of $t$ is given by $F(t)=\int_{\gamma}^{t} f(t)=$ $1-\theta e^{-\theta(t-\gamma)}$ for $t>\gamma$, so that the deterioration rate is $r(t)=(f(t)) /(1-F(t))$ for $t>\gamma$.

(5) The length of time in which the product has no deterioration, $\gamma$, can be estimated by utilizing the random sample data of the product during the past time and statistical maximum method. For simplifying, it is assumed to be a constant.

(6) $M$ is the permissible delay period in payment for the retailer offered by the supplier (upstream credit). During the period, the retailer can use sales revenue to earn the interest with an annual rate $I_{p}$ up to 
the end of $M$. At time $t=M$, the credit is settled and the retailer has to pay the interest at rate $I_{c}$ for the items in stock. $N$ is the permissible delay period in payment for the customer offered by the retailer (downstream credit). During the period, the retailer has to bear the opportunity cost of the revenue which is not settled in time $N$ at the rate of $I_{p}$.

(7) Time horizon is infinite.

(8) $T$ is the length of replenishment cycle. $Q$ is the replenishment quantity per cycle. $T$ and $Q$ are decision variables.

(9) $A, h, c$, and $p$ denote the ordering cost per order, the holding cost per time per item excluding interest charges, the purchasing cost per item, and the selling price per item, respectively. All these parameters are constant and positive.

(10) For $\gamma<T$, there is no deterioration in the time 0 to $T$, where the inventory level is $I_{1}(t)$.

(11) For $T>\gamma$, there is no deterioration in the time 0 to $\gamma$, where the inventory level is $I_{21}(t)$; there is deterioration in the time $\gamma$ to $T$, where the inventory level is $I_{22}(t)$.

(12) $Z_{i}(T)$ is the total average profit which consists of (a) sales profit (SP), (b) the cost of ordering (OC), (c) cost of holding inventory (HC) (excluding interest charges), (d) cost of deterioration (DC), (e) capital opportunity cost (IC), (f) interest earned from the sales revenue (IE), $i=1,2,3$, where $i=1$ indicates $M \leq N, i=2$ indicates $N \leq M \leq N+\gamma$, and $i=3$ indicates $M \geq N+\gamma$.

(13) $T^{*}$ is the optimal replenishment cycle length. $Q^{*}$ is the optimal replenishment quantity. $Z_{i}^{*}$ is the minimum of the total annual cost; that is, $Z_{i}^{*}=Z_{i}\left(T^{*}\right)$.

\section{Model Formulation}

First, we model the demand rate $D(N)$ w.r.t. $N$. According to Jaggi et al. [42] and Thangam and Uthayakumar [35], the marginal effect of credit period on sales is proportional to the unrealized market demand without any delay. Under the assumption, demand can be defined in the following two ways.

(1) The demand function of demand can be represented as a differential difference equation

$$
D(N+1)-D(N)=r(\beta-D(N)) .
$$

(2) The demand rate can be depicted by the partial differential equation

$$
\frac{\partial D(N)}{\partial N}=r(\beta-D(N)) .
$$

In both (1) and (2), $0 \leq r<1, \beta$ is the maximum value of demand rate over the planning horizon. Boundary conditions

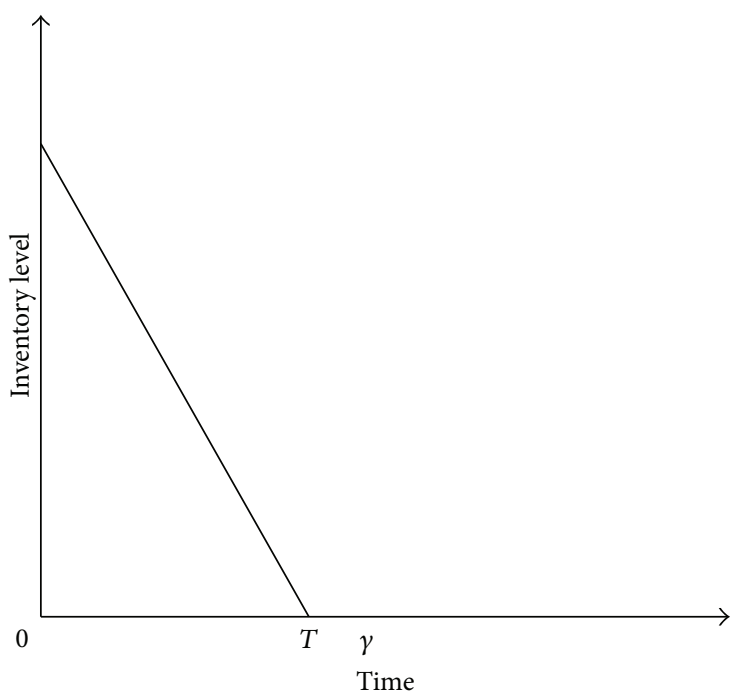

FIGURE 1: Inventory system for $T \leq \gamma$.

are $D(N \rightarrow 0)=\alpha, D(N \rightarrow \infty)=\beta$. The solutions for $(1)$ and (2) are

$$
\begin{gathered}
\text { Type 1: } D(N)=\beta-(\beta-\alpha) e^{-r N}, \\
\text { Type 2: } D(N)=\beta-(\beta-\alpha)(1-r)^{N} .
\end{gathered}
$$

The two types of demand functions are adopted in the following analysis.

The inventory system evolves as follows: $Q$ units of the items arrived at the warehouse at the beginning of each cycle.

When $T \leq \gamma$, there is no deterioration in a single cycle. The inventory system is depicted in Figure 1.

The inventory level decreases owing to the constant demand rate during the whole cycle. It is given that

$$
I_{1}(t)=Q-D t, \quad T \leq \gamma .
$$

When $T \geq \gamma$, there is no deterioration in the time interval $[0, \gamma]$. After that, in the time interval $[\gamma, T]$, items deteriorates at a constant deterioration rate $\theta$, which is shown in Figure 2.

The inventory level decreases owing to the demand rate in time $[0, \gamma]$, which is given by

$$
I_{21}(t)=Q-D t, \quad 0 \leq t \leq \gamma .
$$

In time $[\gamma, T]$, the inventory level declines owing to both the demand rate and the deterioration. Thus, the inventory level is represented by the partial differential equation

$$
\frac{\partial I_{22}(t)}{\partial t}=-D-\theta I_{22}(t), \quad \gamma \leq t \leq T,
$$

with the boundary condition $I_{22}(T)=0$.

The solution of (7) is

$$
I_{22}(t)=\frac{D}{\theta}\left[e^{\theta(T-t)}-1\right], \quad \gamma \leq t \leq T .
$$




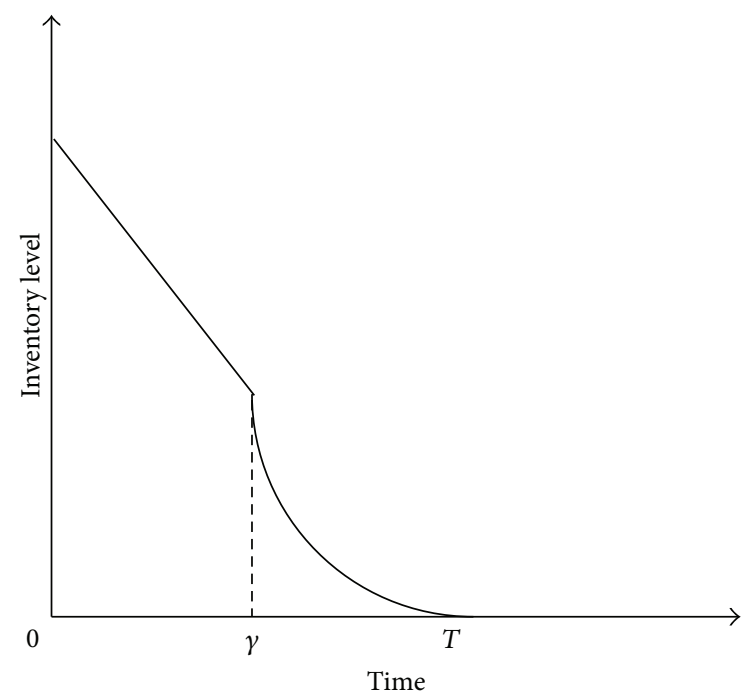

FIGURE 2: Inventory system for $T \geq \gamma$.

Considering the continuity of $I_{21}(t)$ and $I_{22}(t)$ at time $t=\gamma$, it follows from (5) and (7) that

$$
I_{21}(\gamma)=I_{21}(\gamma)=Q-D \gamma=\frac{D}{\theta}\left[e^{\theta(T-\gamma)}-1\right],
$$

which implies that the ordering quantity per cycle is

$$
Q=D \gamma+\frac{D}{\theta}\left[e^{\theta(T-\gamma)}-1\right] .
$$

Then substitute (10) into (6), we have

$$
I_{21}(t)=D(\gamma-t)+\frac{D}{\theta}\left[e^{\theta(T-\gamma)}-1\right], \quad 0 \leq t \leq \gamma .
$$

The total annual relevant cost consists of the following five parts.

(a) Sales profit (SP):

$$
\mathrm{SP}=(p-c) D .
$$

(b) Cost of ordering cost per year (OC):

$$
\mathrm{OC}=\frac{A}{T} .
$$

(c) Cost of holding inventory (HC): There are two possible situations based on the value of $T$ and $\gamma$. When $T \leq \gamma$, the inventory system is the first type shown in Figure 1. When $T \geq \gamma$, the inventory system is the second type depicted in Figure 2. Consequently, the inventory holding cost is given by

$$
\mathrm{HC}= \begin{cases}\frac{h}{T} \int_{0}^{T} I_{1}(t) d t & T \leq \gamma \\ \frac{h}{T}\left(\int_{0}^{\gamma} I_{21}(t) d t+\int_{\gamma}^{T} I_{22}(t) d t\right) & T \geq \gamma .\end{cases}
$$

(d) Cost of deterioration items (DC): For $T \leq \gamma$, there is no deterioration. For $T \geq \gamma$, the cost of deteriorated items is $c(Q-D T) / T$. So, the deterioration cost is given by

$$
\mathrm{DC}= \begin{cases}\frac{c(Q-D T)}{T} & T \geq \gamma \\ 0 & T \leq \gamma .\end{cases}
$$

(e) Opportunity cost (IC) and interest earned from sales revenue (IE): In order to establish the total relevant inventory cost function, we consider three cases: Case 1. $M \leq N$; Case 2. $N \leq M \leq N+\gamma$; and Case 3 . $M \geq N+\gamma$.

Case $1(M \leq N)$. In this case, there are two circumstances: $T \leq \gamma$ and $T \geq \gamma$. And, when $M \leq N$, there is no interest earned by the retailer.

(1) $T \leq \gamma$. The inventory system is depicted in Figure 3 . The retailer has the opportunity cost and has no interest earned. The opportunity cost is calculated as

$$
\mathrm{IC}_{11}=\frac{c I_{c}}{T}\left((N-M) Q+\frac{D T^{2}}{2}\right) .
$$

The total average profit function is

$$
\begin{aligned}
Z_{11}(T, N) & =\mathrm{SP}-\left(\mathrm{OC}+\mathrm{HC}+\mathrm{DC}+\mathrm{IC}_{12}\right) \\
& =(p-c) D-\frac{A}{T}-\frac{\left(h+c I_{c}\right) D T}{2}-c I_{c}(N-M) D .
\end{aligned}
$$

(2) $T \geq \gamma$. The inventory system is depicted in Figure 4 . The retailer has the opportunity cost and has no interest earned. The opportunity cost is calculated as

$$
\mathrm{IC}_{12}=\frac{c I_{c}}{T}\left((N-M) Q+\int_{0}^{\gamma} I_{21}(t) d t+\int_{\gamma}^{T} I_{22}(t) d t\right) .
$$

The total average profit function is

$$
\begin{aligned}
& Z_{12}(T, N) \\
&=\mathrm{SP}-\left(\mathrm{OC}+\mathrm{HC}+\mathrm{DC}+\mathrm{IC}_{12}\right) \\
&=(p-c) D-\frac{A}{T}+\frac{\left(h+c I_{c}\right) D}{T} \\
& \quad \times\left(\frac{\gamma^{2}}{2}+\frac{\gamma}{\theta}\left(e^{\theta(T-\gamma)}-1\right)+\frac{1}{\theta^{2}}\left(e^{\theta(T-\gamma)}-\theta(T-\gamma)-1\right)\right) \\
&-\frac{\left(c+c I_{c}(N-M)\right) D}{T}\left(\gamma+\frac{1}{\theta}\left(e^{\theta(T-\gamma)}-1\right)\right)+c D .
\end{aligned}
$$

The problem of Case 1 is to maximize the function

$$
Z_{1}(T, N)= \begin{cases}Z_{11}(T, N) & T \leq \gamma \\ Z_{12}(T, N) & T \geq \gamma .\end{cases}
$$




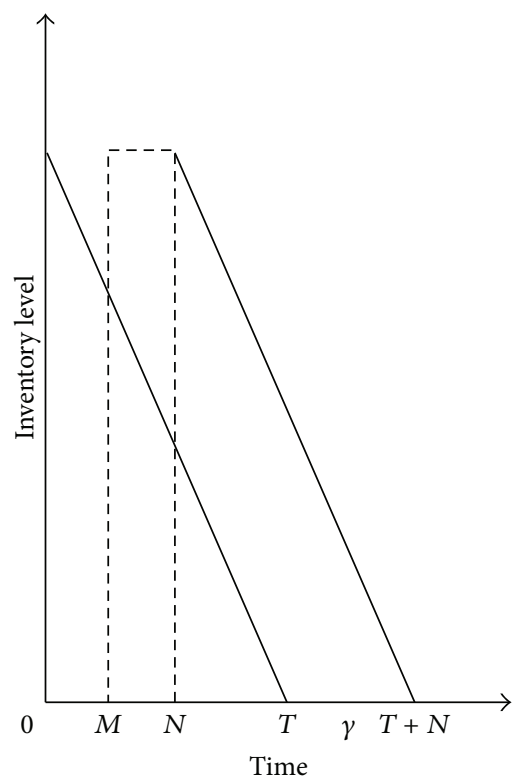

(a)

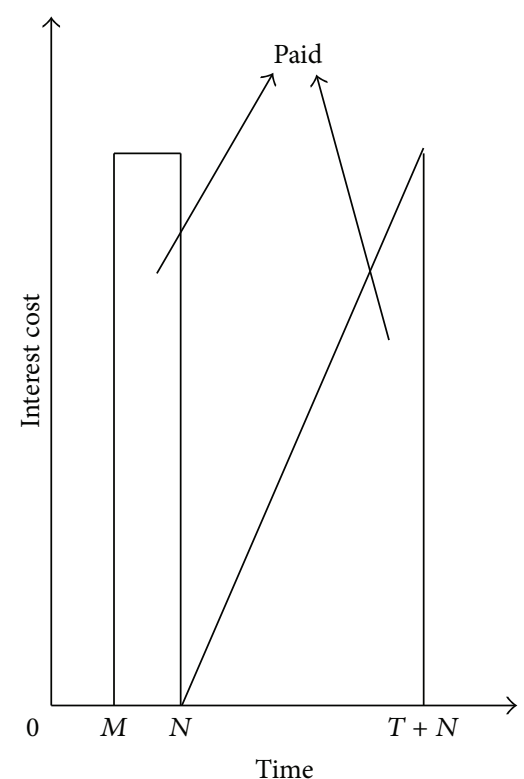

(b)

FIgURE 3: Inventory system for Case 1 when $T \leq \gamma$.

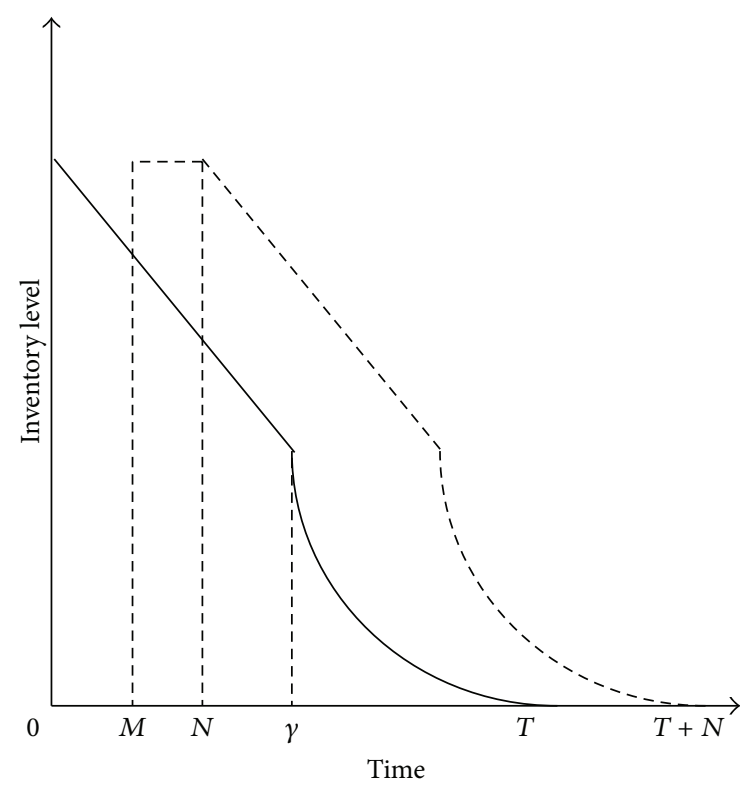

(a)

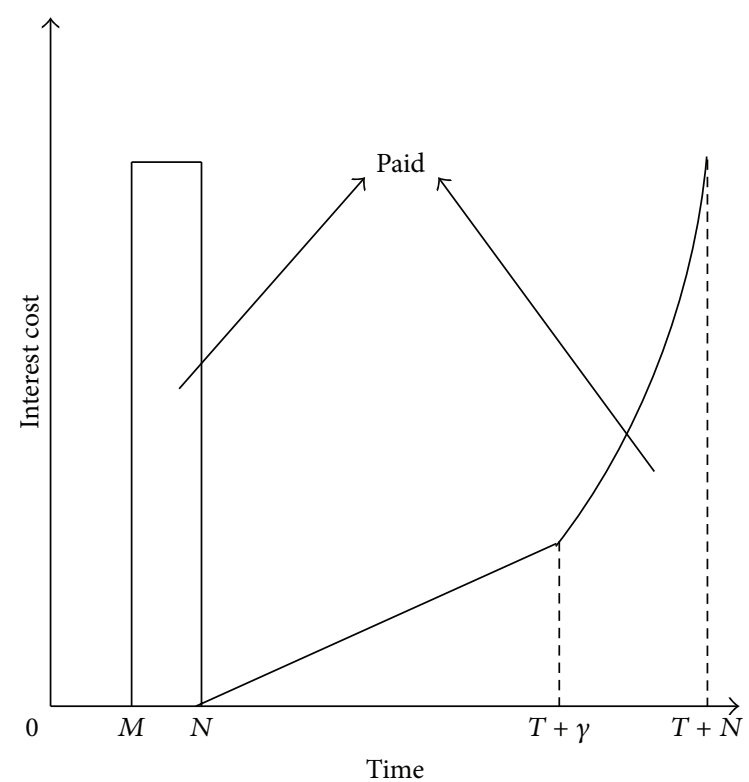

(b)

FIGURE 4: Inventory system for Case 1 when $T \geq \gamma$.

Case $2(N \leq M \leq N+\gamma)$. In this case, there are three circumstances: $T \leq M-N, M-N \leq T \leq \gamma$, and $T \geq \gamma$.

(1) $T \leq M-N$. The inventory system is depicted in Figure 5 . The retailer has no opportunity cost and only has the interest earned. The interest earned per cycle is calculated as

$$
\mathrm{IE}_{21}=\frac{p I_{p}}{T} \cdot\left(\frac{D T^{2}}{2}+D T(M-T-N)\right) .
$$

The total average profit function is

$$
\begin{aligned}
Z_{21}(T, N)= & S P-\left(\mathrm{OC}+\mathrm{HC}+\mathrm{DC}-\mathrm{IE}_{21}\right) \\
= & (p-c) D-\frac{A}{T}-\frac{h D T}{2}+\frac{p I_{p}}{T} \\
& \cdot\left(\frac{D T^{2}}{2}+D T(M-T-N)\right) .
\end{aligned}
$$




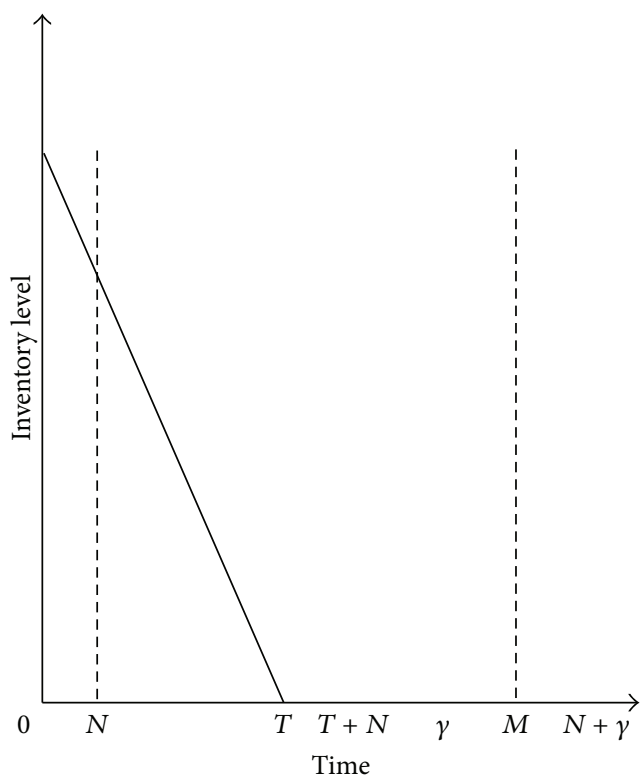

(a)

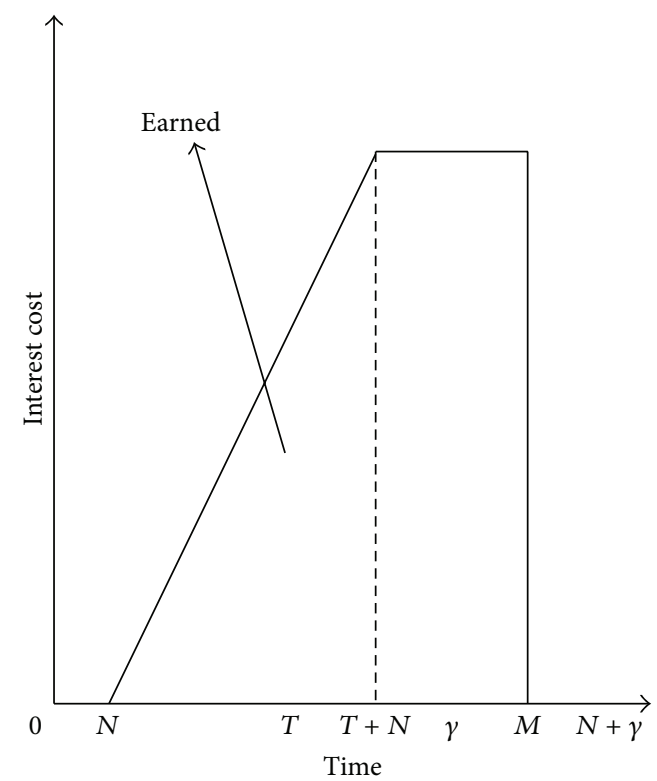

(b)

FIgURE 5: Inventory system for Case 2 when $T \leq M-N$.

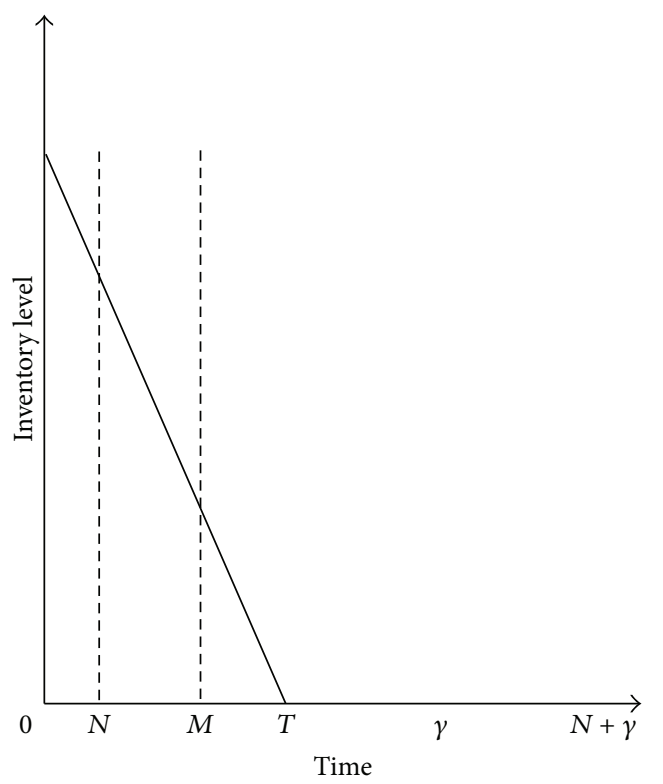

(a)

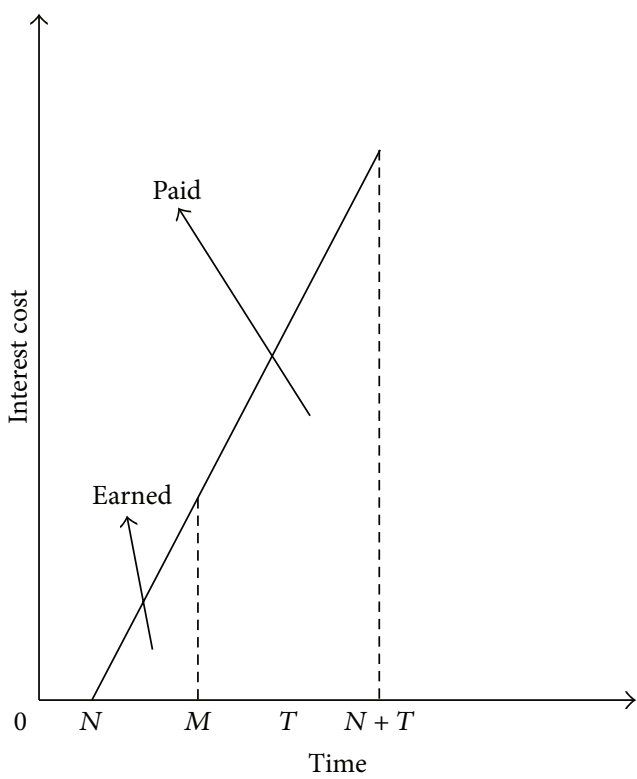

(b)

Figure 6: Inventory system for Case 2 when $M-N \leq T \leq \gamma$.

(2) $M-N \leq T \leq \gamma$. The inventory system is depicted in Figure 6 . The opportunity cost per cycle is calculated as

$$
\mathrm{IC}_{22}=\frac{c I_{c}}{T} \cdot \frac{D(T+N-M)^{2}}{2} .
$$

The interest earned per cycle is calculated as

$$
\mathrm{IE}_{22}=\frac{p I_{p}}{T} \cdot \frac{D(M-N)^{2}}{2} .
$$

The total average profit function is

$$
\begin{aligned}
Z_{22}(T, N)= & S P-\left(\mathrm{OC}+\mathrm{HC}+\mathrm{DC}+\mathrm{IC}_{22}-\mathrm{IE}_{22}\right) \\
= & (p-c) D-\frac{A}{T}-\frac{h D T}{2}-\frac{c I_{c}}{T} \\
& \cdot \frac{D(T+N-M)^{2}}{2}+\frac{p I_{p}}{T} \cdot \frac{D(M-N)^{2}}{2} .
\end{aligned}
$$




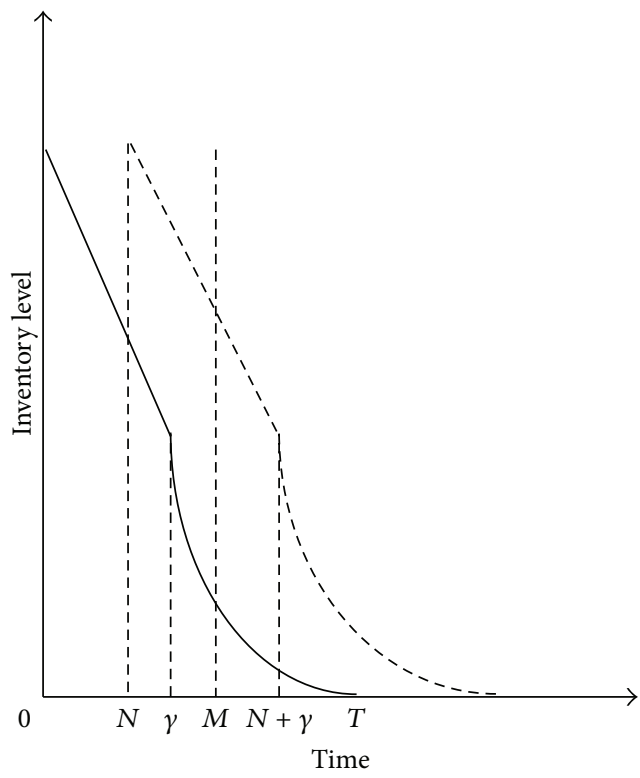

(a)

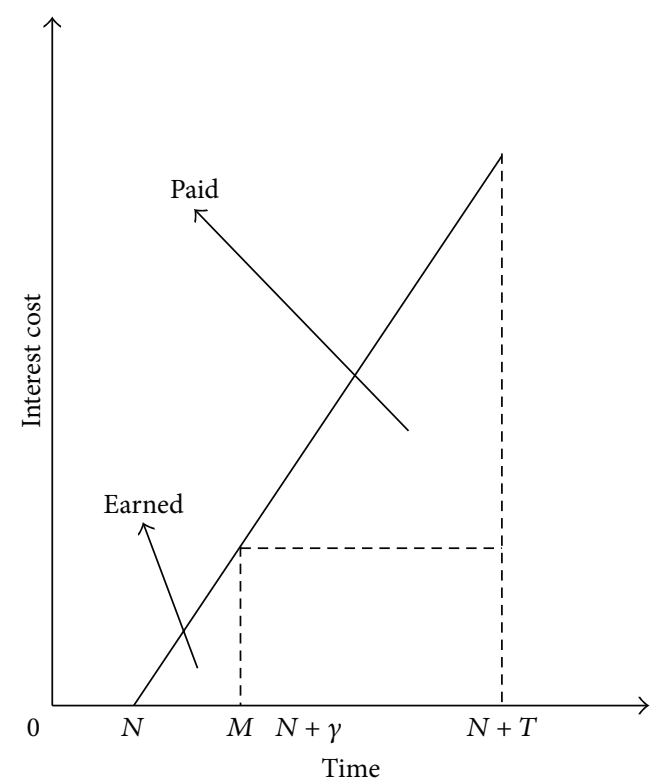

(b)

FIGURE 7: Inventory system for Case 2 when $T \geq \gamma$.

(3) $T \geq \gamma$. The inventory system is depicted in Figure 7. The opportunity cost per cycle is calculated as

$$
\mathrm{IC}_{23}=\frac{c I_{c}}{T}\left(\int_{M-N}^{\gamma} I_{21}(t) d t+\int_{\gamma}^{T} I_{22}(t) d t\right) .
$$

The interest earned per cycle is calculated as

$$
\mathrm{IE}_{23}=\frac{p I_{p}}{T} \cdot \frac{D(M-N)^{2}}{2} .
$$

The total average profit function is

$$
\begin{array}{r}
Z_{23}(T, N) \\
=\mathrm{SP}-\left(\mathrm{OC}+\mathrm{HC}+\mathrm{DC}+\mathrm{IC}_{23}-\mathrm{IE}_{23}\right) \\
=(p-c) D-\left(A+\frac{\left(h+c I_{c}\right) D \gamma^{2}}{2}-c I_{c}(M-N) D \gamma\right. \\
+\frac{c I_{c}(M-N)^{2} D}{2} \\
\left.+c D \gamma-\frac{p I_{p}(M-N)^{2} D}{2}\right) \times T^{-1} \\
-\left(\frac{h \gamma D+c I_{c}(\gamma-M+N) D+c D}{\theta}\right) \frac{e^{\theta(T-\gamma)}-1}{T} \\
-\frac{\left(h+c I_{c}\right) D}{\theta^{2}} \frac{e^{\theta(T-\gamma)}-\theta(T-\gamma)-1}{T}+c D .
\end{array}
$$

The problem of Case 2 is to maximize the function

$$
Z_{2}(T, N)= \begin{cases}Z_{21}(T, N) & T \leq M-N \\ Z_{22}(T, N) & M-N \leq T \leq \gamma \\ Z_{23}(T, N) & T \geq \gamma .\end{cases}
$$

Case $3(M \geq N+\gamma)$. In this case, there are three circumstances: $T \leq \gamma, \gamma \leq T \leq M-N$, and $T \geq M-N$.

(1) $T \leq \gamma$. The inventory system is depicted in Figure 8 . There is no opportunity cost under this circumstance. The interest earned per cycle is calculated as

$$
\mathrm{IE}_{31}=\frac{p I_{p}}{T} \cdot\left(\frac{D T^{2}}{2}+D T(M-T-N)\right) .
$$

The total average profit function is

$$
\begin{aligned}
Z_{31}(T, N)= & \mathrm{SP}-\left(\mathrm{OC}+\mathrm{HC}+\mathrm{DC}-\mathrm{IE}_{31}\right) \\
= & (p-c) D-\frac{A}{T}-\frac{h D T}{2}+\frac{p I_{p}}{T} \\
& \cdot\left(\frac{D T^{2}}{2}+D T(M-T-N)\right) .
\end{aligned}
$$

(2) $\gamma \leq T \leq M-N$. The inventory system is depicted in Figure 9. There is no opportunity cost under this circumstance. The interest earned per cycle is calculated as

$$
\mathrm{IE}_{32}=\frac{p I_{p}}{T} \cdot\left(\frac{D T^{2}}{2}+D T(M-T-N)\right) .
$$




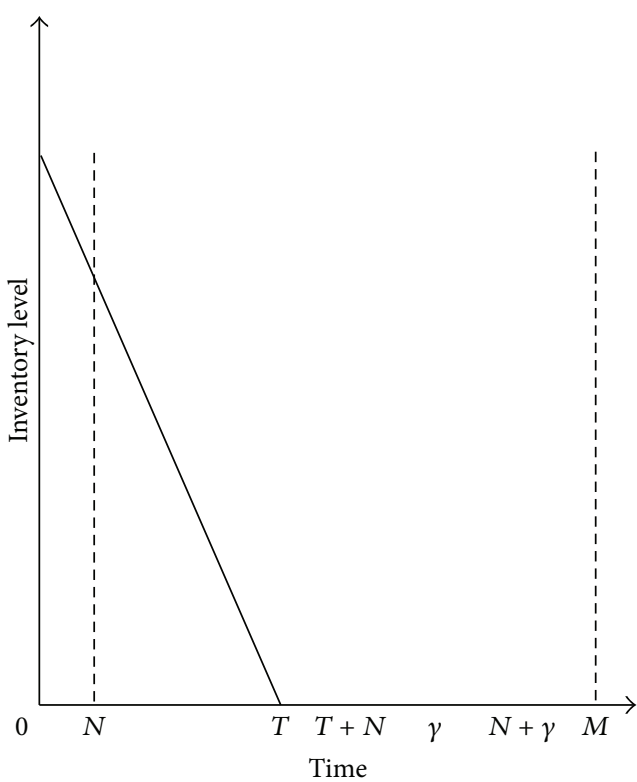

(a)

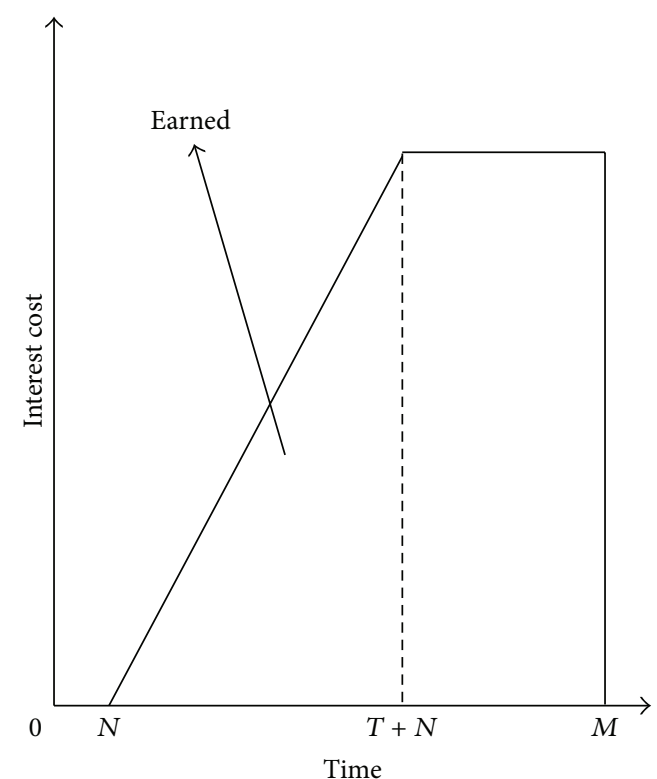

(b)

FIGURE 8: Inventory system for Case 3 when $T \leq \gamma$.

The total average profit function is

$$
\begin{aligned}
& Z_{32}(T, N) \\
&= \mathrm{SP}-\left(\mathrm{OC}+\mathrm{HC}+\mathrm{DC}-\mathrm{IE}_{32}\right) \\
&=(p-c) D-\frac{A}{T}-\frac{h D}{T} \\
& \times\left(\frac{\gamma^{2}}{2}+\frac{\gamma}{\theta}\left(e^{\theta(T-\gamma)}-1\right)+\frac{1}{\theta^{2}}\left(e^{\theta(T-\gamma)}-\theta(T-\gamma)-1\right)\right) \\
&-\frac{c D}{T}\left(\gamma+\frac{1}{\theta}\left(e^{\theta(T-\gamma)}-1\right)\right)+c D+\frac{p I_{p}}{T} \\
& \cdot\left(\frac{D T^{2}}{2}+D T(M-T-N)\right) .
\end{aligned}
$$

(3) $T \geq M-N$. The inventory system is depicted in Figure 10 . The opportunity cost per cycle is calculated as

$$
\mathrm{IC}_{33}=\frac{c I_{c}}{T} \cdot \int_{M-N}^{T} I_{22}(t) d t
$$

The interest earned per cycle is calculated as

$$
\mathrm{IE}_{33}=\frac{p I_{p}}{T} \cdot \frac{D(M-N)^{2}}{2} .
$$

The total average profit function is

$$
\begin{aligned}
Z_{33}( & T, N) \\
= & \mathrm{SP}-\left(\mathrm{OC}+\mathrm{HC}+\mathrm{DC}+\mathrm{IC}_{31}-\mathrm{IE}_{31}\right) \\
= & (p-c) D-\frac{A}{T}-\frac{h D}{T} \\
& \times\left(\frac{\gamma^{2}}{2}+\frac{\gamma}{\theta}\left(e^{\theta(T-\gamma)}-1\right)+\frac{1}{\theta^{2}}\left(e^{\theta(T-\gamma)}-\theta(T-\gamma)-1\right)\right) \\
& +\frac{c D}{T}\left(\gamma+\frac{1}{\theta}\left(e^{\theta(T-\gamma)}-1\right)\right) \\
& +c D-\frac{c I_{c}}{T}\left(\frac{e^{\theta(T-M+N)}-1}{\theta^{2}}-\frac{T+M-N}{\theta}\right) \\
& +\frac{p I_{p}(M-N)^{2} D}{2 T} .
\end{aligned}
$$

The problem of Case 3 is to maximize the following function:

$$
Z_{3}(T, N)= \begin{cases}Z_{31}(T, N) & T \leq \gamma \\ Z_{32}(T, N) & \gamma \leq T \leq M-N \\ Z_{33}(T, N) & T \geq M-N\end{cases}
$$

\section{Solution Procedure}

Now, we shall determine the optimal cycle length and downstream credit period for the three cases under maximizing the total average profit function. To find the optimal solution, say $\left(T^{*}, N^{*}\right)$, for $Z_{i}(T, N)(i=1,2,3)$, the following procedures 


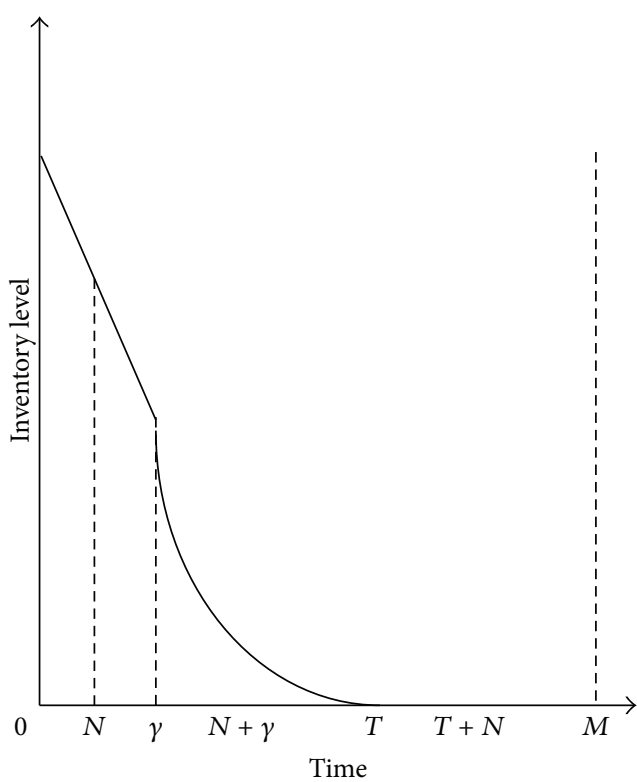

(a)

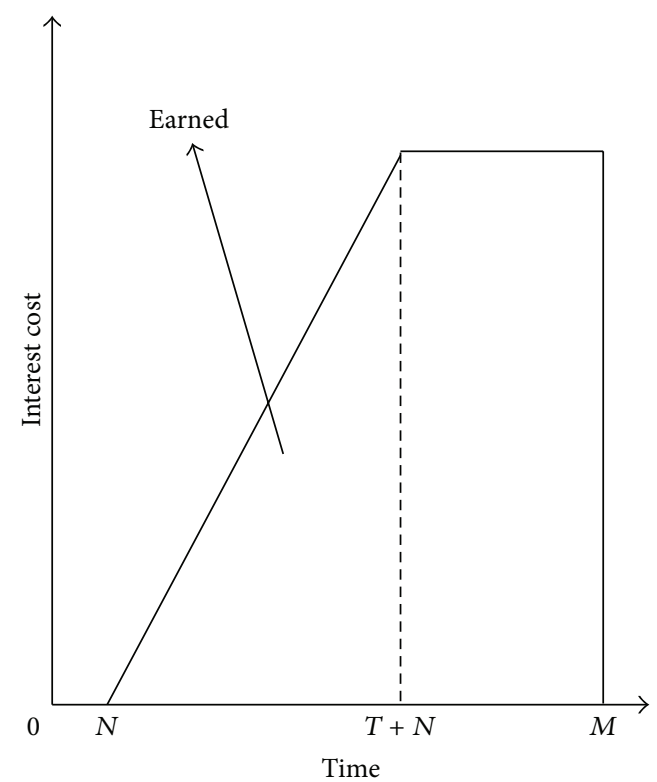

(b)

FIGURE 9: Inventory system for Case 3 when $\gamma \leq T \leq M-N$.

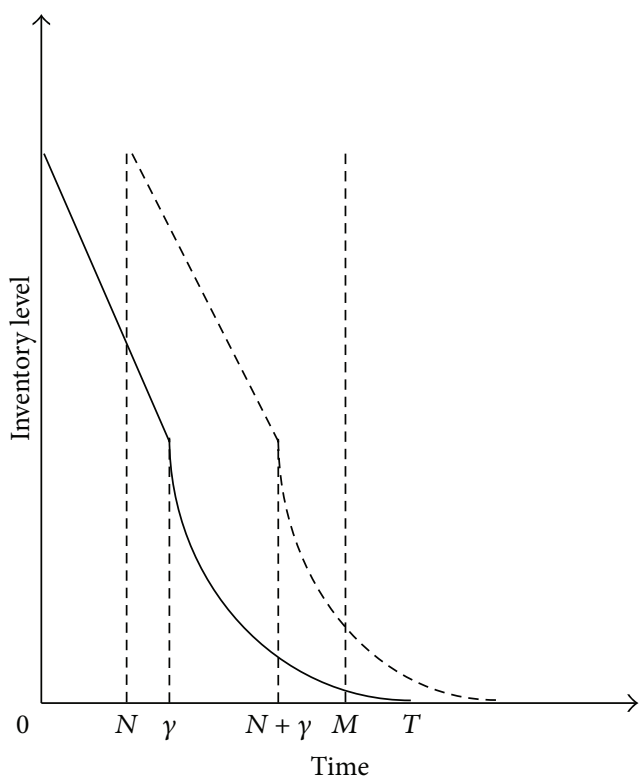

(a)

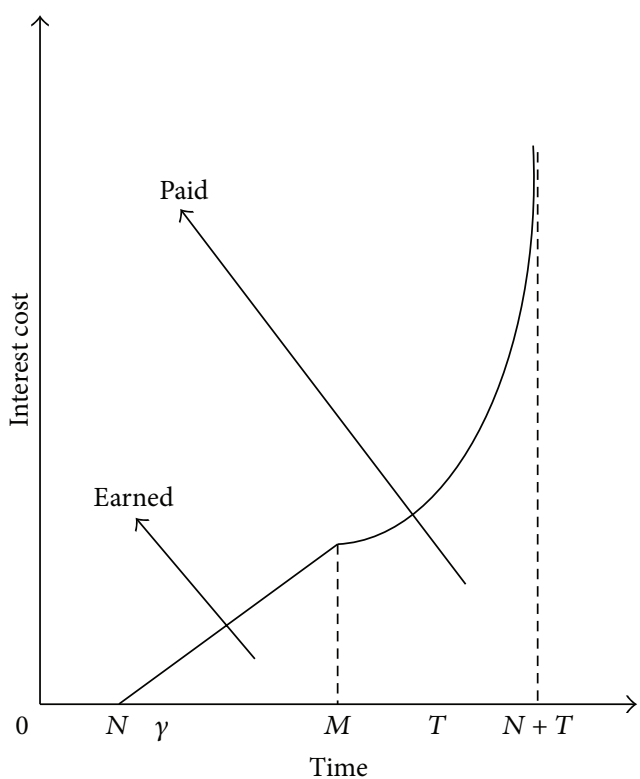

(b)

Figure 10: Inventory system for Case 3 when $T \geq M-N$.

are considered. We first analyze the property of the optimal replenishment cycle length for any fixed $N(N=1,2,3, \ldots)$.

Case $1(M \leq N)$. The problem is to minimize function (20). It can be calculated that $Z_{11}(\gamma)=Z_{12}(\gamma)$. So function (20) is continuous at point $T=\gamma$. The first-order necessary condition for $Z_{11}(T)$ in (13) to be maximized is

$$
\frac{\partial Z_{11}(T \mid N)}{\partial T}=\frac{A}{T^{2}}-\frac{\left(h+c I_{c}\right) D}{2}=0 .
$$

The second-order sufficient condition is

$$
\frac{\partial^{2} Z_{11}(T \mid N)}{\partial T^{2}}=-\frac{2 A}{T^{3}}<0 .
$$

Consequently, $Z_{11}(T \mid N)$ is a concave function of $T$. Thus, there exists a unique value of $T$ (say $T_{11}$ ) which minimize $Z_{11}(T \mid N)$ as

$$
T_{11}=\sqrt{\frac{2 A}{\left(h+c I_{c}\right) D}} .
$$


To ensure $T \leq \gamma$, we substitute (40) into inequality $T \leq \gamma$ and we obtain

$$
0<2 A \leq\left(h+c I_{c}\right) D \gamma^{2} .
$$

Likewise, the first-order necessary condition for $Z_{12}(T \mid N)$ in (19) to be maximized is

$$
\begin{aligned}
\frac{\partial Z_{12}(T \mid N)}{\partial T} & \frac{\left[A+\left(h+c I_{c}\right) D \gamma^{2} / 2+c D \gamma+c I_{c}(N-M) D \gamma\right]}{T^{2}} \\
= & -\left[\frac{\left(h+c I_{c}\right) D \gamma}{\theta}+\frac{c+c I_{c}(N-M)}{\theta} D\right] \\
& \times\left(\frac{\theta e^{\theta(T-\gamma)}}{T}-\frac{e^{\theta(T-\gamma)}}{T^{2}}+\frac{1}{T^{2}}\right) \\
& -\frac{\left(h+c I_{c}\right) D}{\theta^{2}}\left(\frac{\theta e^{\theta(T-\gamma)}}{T}-\frac{e^{\theta(T-\gamma)}}{T^{2}}+\frac{1-\theta \gamma}{T^{2}}\right)=0 .
\end{aligned}
$$

By using the analogous arguments, we can easily obtain that

$$
\begin{aligned}
& {\left[A+\frac{\left(h+c I_{c}\right) D \gamma^{2}}{2}+c D \gamma+c I_{c}(N-M) D \gamma\right]} \\
& -\left[\frac{\left(h+c I_{c}\right) D \gamma}{\theta}+\frac{c+c I_{c}(N-M)}{\theta} D\right] \\
& \quad \times\left(\theta T e^{\theta(T-\gamma)}-e^{\theta(T-\gamma)}+1\right) \\
& \quad-\frac{\left(h+c I_{c}\right) D}{\theta^{2}}\left(\theta e^{\theta(T-\gamma)}-e^{\theta(T-\gamma)}+1-\theta \gamma\right)=0 .
\end{aligned}
$$

It is not easy to find a closed form solution of $T$ from (43). But we can show that the value of $T$ satisfy (43) not only exists but also is unique. So we have the following lemma.

Lemma 1. For a given $N$, when $M \leq N$,

(a) if $2 A \geq\left(h+c I_{c}\right) D \gamma^{2}$, then the solution of $T \in[\gamma,+\infty)$ (say $\left.T_{12}\right)$ in (43) not only exists but also is unique.

(b) if $0<2 A<\left(h+c I_{c}\right) D \gamma^{2}$, then the solution of $T \in$ $[\gamma,+\infty)$ in (43) does not exist.

Proof. See Appendix A.

According to Lemma 1, we have the following result.

Lemma 2. For a given $N$, when $M \leq N$,

(a) if $2 A \geq\left(h+c I_{c}\right) D \gamma^{2}$, then the total relevant cost $Z_{12}(T$ | $N)$ has the global maximum value at point $T=T_{12}$, where $T_{12} \in[\gamma,+\infty)$ and satisfies (43).

(b) if $0<2 A<\left(h+c I_{c}\right) D \gamma^{2}$, then the total relevant cost $Z_{12}(T \mid N)$ has maximum value at the boundary point $T=\gamma$.

\section{Proof. See Appendix A.}

For notational convenience, we mark that $\Delta_{1}=(h+$ $\left.c I_{c}\right) D \gamma^{2}$. Combining the above mentioned inequality (41), Lemmas 1 and 2 and the assumption $M \leq N$, we can obtain the following theorem.

Theorem 3. For a given $N$, when $M \leq N$,

(a) if $2 A<\Delta_{1}$, then $Z_{1}\left(T^{*} \mid N\right)=Z_{11}\left(T_{11} \mid N\right)$ and $T^{*}=T_{11}$

(b) if $2 A \geq \Delta_{1}$, then $Z_{1}\left(T^{*} \mid N\right)=\max \left(Z_{12}\left(T_{12} \mid\right.\right.$ $\left.N), Z_{12}(\gamma \mid N)\right)$. Hence $T^{*}$ is $T_{12}$ or $\gamma$ associated with lower total average profit.

Case $2(N \leq M \leq N+\gamma)$. The problem is to maximize function (29). It can be calculated that $Z_{21}(M-M \mid N)=$ $Z_{22}(M-M \mid N), Z_{22}(\gamma \mid N)=Z_{23}(\gamma \mid N)$. So function (29) is continuous at point $T=M-N$ and $T=\gamma$.

The first-order necessary condition for $Z_{21}(T \mid N)$ in (22) to be minimized is

$$
\frac{\partial Z_{21}(T \mid N)}{\partial T}=\frac{A}{T^{2}}-\frac{\left(h+p I_{p}\right) D}{2}=0 .
$$

The second-order sufficient condition is

$$
\frac{\partial^{2} Z_{21}(T \mid N)}{\partial T^{2}}=-\frac{2 A}{T^{3}}<0 .
$$

Consequently, $Z_{21}(T \mid N)$ is a concave function of $T$. Thus, there exists a unique value of $T$ (say $T_{21}$ ) which minimize $Z_{21}(T \mid N)$ as

$$
T_{21}=\sqrt{\frac{2 A}{\left(h+p I_{p}\right) D}} .
$$

To ensure $T \leq M-N$, we substitute (46) into inequality $T \leq$ $M-N$ and obtain

$$
0<2 A \leq\left(h+p I_{p}\right) D(M-N)^{2} .
$$

The first-order necessary condition for $Z_{22}(T \mid N)$ in (25) to be maximized is

$$
\begin{aligned}
& \frac{\partial Z_{22}(T \mid N)}{\partial T} \\
& \quad=\frac{A}{T^{2}}-\frac{\left(h+c I_{c}\right) D}{2}-\frac{p I_{p}(M-N)^{2} D}{2 T^{2}}+\frac{c I_{c}(M-N)^{2} D}{2 T^{2}} \\
& =0 .
\end{aligned}
$$

The second-order sufficient condition is

$$
\frac{\partial^{2} Z_{22}(T \mid N)}{\partial T^{2}}=-\frac{2 A}{T^{3}}<0 .
$$

Consequently, $Z_{22}(T \mid N)$ is a concave function of $T$. Thus there exists a unique value of $T$ (say $T_{22}$ ) which maximizes $Z_{22}(T \mid N)$ as

$$
T=\sqrt{\frac{2 A+\left(c I_{c}-p I_{p}\right)(M-N)^{2} D}{\left(h+c I_{c}\right) D}} .
$$


To ensure $M-N<T \leq \gamma$, we substitute (50) into inequality $M-N<T \leq \gamma$ and obtain

$$
\begin{aligned}
\left(h+p I_{p}\right) D(M-N)^{2} & \\
& <2 A \leq\left(h+c I_{c}\right) \gamma^{2} D-\left(c I_{c}-p I_{p}\right)(M-N)^{2} D .
\end{aligned}
$$

Likewise, the first-order necessary condition for $Z_{23}(T \mid N)$ in $(28)$ to be maximized is

$$
\begin{aligned}
\frac{\partial Z_{23}(T \mid N)}{\partial T} & {\left[A+\frac{\left(h+c I_{c}\right) D \gamma^{2}}{2}-c I_{c}(M-N) D \gamma\right.} \\
= & \\
& \left.+\frac{c I_{c}(M-N)^{2} D}{2}+c D \gamma-\frac{p I_{p}(M-N)^{2} D}{2}\right] \times\left(T^{2}\right)^{-1} \\
& -\left[\frac{h \gamma D+c I_{c}(\gamma-M+N) D+c D}{\theta}\right] \\
& \times\left(\frac{\theta e^{\theta(T-\gamma)}}{T}-\frac{e^{\theta(T-\gamma)}}{T^{2}}+\frac{1}{T^{2}}\right) \\
& -\frac{\left(h+c I_{c}\right) D}{\theta^{2}}\left(\frac{\theta e^{\theta(T-\gamma)}}{T}-\frac{e^{\theta(T-\gamma)}}{T^{2}}+\frac{1-\theta \gamma}{T^{2}}\right)=0 .
\end{aligned}
$$

By using the analogous arguments, we can easily obtain that

$$
\begin{aligned}
& {\left[A+\frac{\left(h+c I_{c}\right) D \gamma^{2}}{2}-c I_{c}(M-N) D \gamma\right.} \\
& \left.+\frac{c I_{c}(M-N)^{2} D}{2}+c D \gamma-\frac{p I_{p}(M-N)^{2} D}{2}\right] \\
& -\left[\frac{h \gamma D+c I_{c}(\gamma-M+N) D+c D}{\theta}\right] \\
& \quad \times\left(\theta T e^{\theta(T-\gamma)}-e^{\theta(T-\gamma)}+1\right) \\
& -\frac{\left(h+c I_{c}\right) D}{\theta^{2}}\left(\theta e^{\theta(T-\gamma)}-e^{\theta(T-\gamma)}+1-\theta \gamma\right)=0 .
\end{aligned}
$$

So, we have the following lemma.

Lemma 4. For a given $N$, when $N \leq M \leq N+\gamma$,

(a) if $2 A \geq\left(h+c I_{c}\right) \gamma^{2} D-\left(c I_{c}-p I_{p}\right)(M-N)^{2} D$, then the solution of $T \in[\gamma,+\infty)$ (say $\left.T_{23}\right)$ in (53) not only exists but also is unique.

(b) if $2 A<\left(h+c I_{c}\right) \gamma^{2} D-\left(c I_{c}-p I_{p}\right)(M-N)^{2} D$, then the solution of $T \in[\gamma,+\infty)$ in (53) does not exist.

Proof. See Appendix B.

According to Lemma 4, we have the following result.
Lemma 5. For a given $N$, when $N \leq M \leq N+\gamma$,

(a) if $2 A \geq\left(h+c I_{c}\right) \gamma^{2} D-\left(c I_{c}-p I_{p}\right)(M-N)^{2} D$, then the total average profit $Z_{23}(T \mid N)$ has the global maximum value at point $T=T_{23}$, where $T_{23} \in[\gamma,+\infty)$ and satisfies (52);

(b) if $2 A<\left(h+c I_{c}\right) \gamma^{2} D-\left(c I_{c}-p I_{p}\right)(M-N)^{2} D$, then the total average profit $Z_{23}(T \mid N)$ has maximum value at the boundary point $T=\gamma$.

Proof. See Appendix B.

For notational convenience, we mark that

$$
\begin{gathered}
\Delta_{2}=\left(h+p I_{p}\right) D(M-N)^{2}, \\
\Delta_{3}=\left(h+c I_{c}\right) \gamma^{2} D-\left(c I_{c}-p I_{p}\right)(M-N)^{2} D .
\end{gathered}
$$

Combining the forementioned mentioned equations (47) and (51), Lemmas 4 and 5, and the assumption $N \leq M \leq N+\gamma$, we can obtain the following theorem.

Theorem 6. For a given $N$, when $N \leq M \leq N+\gamma$,

(a) if $0<2 A<\Delta_{2}$, then $Z_{2}\left(T^{*} \mid N\right)=\max \left(Z_{21}\left(T_{21} \mid\right.\right.$ $\left.N), Z_{21}(M-N \mid N)\right)$. Hence $T^{*}$ is $T_{21}$ or $M-N$ associated with higher total average profit;

(b) if $\Delta_{2} \leq 2 A<\Delta_{3}$, then $Z_{2}\left(T^{*} \mid N\right)=\max \left(Z_{22}\left(T_{22} \mid\right.\right.$ $\left.N), Z_{22}(\gamma \mid N)\right)$. Hence $T^{*}$ is $T_{23}$ or $\gamma$ associated with higher total average profit.

(c) if $2 A \geq \Delta_{3}$, then $Z_{2}\left(T^{*} \mid N\right)=Z_{23}\left(T_{23} \mid N\right), T^{*}=$ $T_{23}$.

Case $3(M \geq N+\gamma)$. The problem is to maximize function (37). It can be calculated that $Z_{31}(\gamma \mid N)=Z_{32}(\gamma \mid N)$ and $Z_{32}(M-N \mid N)=Z_{33}(M-N \mid N)$. So function (37) is continuous at point $T=\gamma$ and $T=M-N$.

The first-order necessary condition for $Z_{31}(T \mid N)$ in (31) to be minimized is

$$
\frac{\partial Z_{31}(T \mid N)}{\partial T}=\frac{A}{T^{2}}-\frac{h D}{2}-\frac{p I_{p}}{2}=0
$$

The second-order sufficient condition is

$$
\frac{\partial^{2} Z_{31}(T \mid N)}{\partial T^{2}}=-\frac{2 A}{T^{3}}<0 .
$$

Consequently, $Z_{31}(T \mid N)$ is a convex function of $T$. Thus, there exists a unique value of $T$ ( say $T_{31}$ ) which minimizes $Z_{31}(T \mid N)$ as

$$
T_{31}=\sqrt{\frac{2 A}{\left(h+p I_{p}\right) D}} .
$$

To ensure $T<\gamma$, we substitute (57) into inequality $T<\gamma$ and obtain

$$
0<2 A<\left(h+p I_{p}\right) D \gamma^{2}
$$


Likewise, the first-order necessary condition for $Z_{32}(T \mid N)$ in (33) to be maximized is

$$
\begin{aligned}
& \frac{\partial Z_{32}(T \mid N)}{\partial T} \\
& =\frac{\left(A+h D \gamma^{2} / 2+c D \gamma\right)}{T^{2}}-\left(\frac{h D \gamma+c D}{\theta}\right) \\
& \quad \times\left(\frac{\theta e^{\theta(T-\gamma)}}{T}-\frac{e^{\theta(T-\gamma)}}{T^{2}}+\frac{1}{T^{2}}\right) \\
& \quad-\frac{h D}{\theta^{2}}\left(\frac{\theta e^{\theta(T-\gamma)}}{T}-\frac{e^{\theta(T-\gamma)}}{T^{2}}+\frac{1-\theta \gamma}{T^{2}}\right)-\frac{p I_{p} D}{2}=0 .
\end{aligned}
$$

By using the analogous arguments, we can easily obtain that

$$
\begin{gathered}
\left(A+\frac{h D \gamma^{2}}{2}+c D \gamma\right)-\left(\frac{h D \gamma+c D}{\theta}\right)\left(\theta T e^{\theta(T-\gamma)}-e^{\theta(T-\gamma)}+1\right) \\
-\frac{h D}{\theta^{2}}\left(\theta T e^{\theta(T-\gamma)}-e^{\theta(T-\gamma)}+1-\theta \gamma\right)-\frac{p I_{p} D T^{2}}{2}=0 .
\end{gathered}
$$

Let

$$
\begin{gathered}
\Delta_{4}=\left(h D+p I_{p} D\right) \gamma^{2} \\
\Delta_{5}=-\left(h D \gamma^{2}+2 c D \gamma\right)+2\left(\frac{h D \gamma+c D}{\theta}+\frac{h D}{\theta^{2}}\right) \\
\times\left[\theta(M-N) e^{\theta(M-N-\gamma)}-e^{\theta(M-N-\gamma)}+1\right] \\
-\frac{2 h D \gamma}{\theta}+p I_{p} D(M-N)^{2} .
\end{gathered}
$$

Then, we have the following lemma.

Lemma 7. For a given $N$, when $M \geq N+\gamma$,

(a) if $\Delta_{4} \leq 2 A \leq \Delta_{5}$, then the solution of $T \in[\gamma, M-N]$ (say $T_{32}$ ) in (60) not only exists but also is unique;

(b) if $2 \mathrm{~A}<\Delta_{4}$ or $2 \mathrm{~A}>\Delta_{5}$, then the solution of $\mathrm{T} \in$ $[\gamma, M-N]$ in $(60)$ does not exist.

Proof. See Appendix C.

According to Lemma 7, we have the following result.

Lemma 8. For a given $N$, when $M \geq N+\gamma$,

(a) if $\Delta_{4} \leq 2 A \leq \Delta_{5}$, then the total average profit $Z_{32}$ ( $T$ | $N)$ has the global maximum value at point $T=T_{32}$, where $T_{32} \in[\gamma, M-N]$ and satisfies (60);

(b) if $2 \mathrm{~A}<\Delta_{4}$, then the total average profit $Z_{32}(T \mid N)$ has the maximum value at the boundary point $T=\gamma$;

(c) if $2 \mathrm{~A}>\Delta_{5}$, then the total average profit $Z_{32}(T \mid N)$ has the maximum value at the boundary point $T=M-N$.
Proof. See Appendix C.

Likewise, the first-order necessary condition for $Z_{33}(T$ । $N)$ in (36) to be maximized is

$$
\begin{aligned}
& \frac{\partial Z_{33}(T \mid N)}{\partial T} \\
= & \frac{\left(A+h D \gamma^{2} / 2+c D \gamma-c I_{c}(M-N)-p I_{p}(M-N)^{2} D / 2\right)}{T^{2}} \\
& -\left(\frac{h D \gamma+c D}{\theta}\right)\left(\frac{\theta e^{\theta(T-\gamma)}}{T}-\frac{e^{\theta(T-\gamma)}}{T^{2}}+\frac{1}{T^{2}}\right) \\
& +\frac{h D}{\theta^{2}}\left(\frac{\theta e^{\theta(T-\gamma)}}{T}-\frac{e^{\theta(T-\gamma)}}{T^{2}}+\frac{1-\theta \gamma}{T^{2}}\right) \\
& -\frac{c I_{c}}{\theta^{2}}\left(\frac{\theta e^{\theta(T-M+N)}}{T}-\frac{e^{\theta(T-M+N)}}{T^{2}}+\frac{1}{T^{2}}\right)=0 .
\end{aligned}
$$

By using the analogous arguments, we can easily obtain that

$$
\begin{aligned}
& \left(A+\frac{h D \gamma^{2}}{2}+c D \gamma-c I_{c}(M-N)-\frac{p I_{p}(M-N)^{2} D}{2}\right) \\
& -\left(\frac{h D \gamma+c D}{\theta}\right)\left(\theta T e^{\theta(T-\gamma)}-e^{\theta(T-\gamma)}+1\right) \\
& -\frac{h D}{\theta^{2}}\left(\theta T e^{\theta(T-\gamma)}-e^{\theta(T-\gamma)}+1-\theta \gamma\right) \\
& -\frac{c I_{c}}{\theta^{2}}\left(\theta T e^{\theta(T-M+N)}-e^{\theta(T-M+N)}+1\right)=0 .
\end{aligned}
$$

Also, we have the following lemma.

Lemma 9. For a given $N$, when $M \geq N+\gamma$,

(a) if $2 \mathrm{~A} \geq \Delta_{5}$, then the solution of $T \in[M-N,+\infty$ ) (say $\left.T_{33}\right)$ in (63) not only exists but also is unique;

(b) if $0<2 A<\Delta_{5}$, then the solution of $T \in[M-N$, $+\infty$ ) in (63) does not exist.

Proof. See Appendix D.

According to Lemma 9, we have the following result.

Lemma 10. For a given $N$, when $M \geq N+\gamma$,

(a) if $2 \mathrm{~A} \geq \Delta_{5}$, then the total average profit $Z_{33}(T \mid N)$ has the global maximum value at point $T=T_{33}$, where $T_{33} \in[M-N,+\infty)$ and satisfies (63);

(b) if $0<2 A<\Delta_{5}$, then the total average profit $Z_{33}(T$ I $N)$ has the global maximum value at point $T=M-N$, where $T_{33} \in[M-N,+\infty)$.

Proof. See Appendix D. 
Combining the forementioned mentioned equation (58), Lemmas 7-10, and the assumption $M \geq N+\gamma$, we can obtain the following theorem.

Theorem 11. For a given $N$, when $M \geq N+\gamma$,

(a) if $0<2 A<\Delta_{4}$, then $Z_{3}\left(T^{*} \mid N\right)=\max \left(Z_{31}\left(T_{31} \mid\right.\right.$ $\left.N), Z_{31}(\gamma \mid N)\right)$, Hence $T^{*}$ is $T_{31}$ or $\gamma$ associated with higher total average profit;

(b) if $\Delta_{4} \leq 2 A<\Delta_{5}$, then $Z_{3}\left(T^{*} \mid N\right)=\max \left(Z_{32}\left(T_{32} \mid\right.\right.$ $N), Z_{32}(M-N \mid N)$ ). Hence $T^{*}$ is $T_{21}$ or $M-N$ associated with higher total average profit;

(c) if $2 A \geq \Delta_{5}$, then $Z_{3}\left(T^{*} \mid N\right)=Z_{33}\left(T_{33} \mid N\right)$, and $T^{*}=T_{33}$.

For the downstream credit is an integer according to the assumptions, and interactive algorithms can be used to find the optimal solutions for our model. By summarizing the results in Theorems 3, 6, and 11, an algorithm to illustrate the optimal solution for the model is proposed as follows.

Algorithm 12. Consider the following:

(1) Let $N=1$.

(2) Compare the value of $M, N$, $\gamma$. If $M \leq N$, then go to step 3; If $N \leq M \leq N+\gamma$, then go to step 5; If $M \geq N+\gamma$, then go to step 7 .

(3) Calculate $\Delta_{1}(N)$,

(1) If $2 A<\Delta_{1}$, then $T^{*}=T_{11}$ and $Z_{1}\left(T_{N}^{*}, N\right)=$ $Z_{1}\left(T^{*} \mid N\right)=Z_{11}\left(T_{11} \mid N\right)$.

(2) If $2 A \geq \Delta_{1}$, and

(i) $Z_{12}\left(T_{12} \mid N\right) \geq Z_{12}(\gamma \mid N)$, then $T^{*}=T_{12}$, $Z_{1}\left(T_{N}^{*}, N\right)=Z_{1}\left(T^{*} \mid N\right)=Z_{12}\left(T_{12} \mid N\right)$;

(ii) $Z_{12}\left(T_{12} \mid N\right)<Z_{12}(\gamma \mid N)$, then $T^{*}=\gamma$, $Z_{1}\left(T_{N}^{*}, N\right)=Z_{1}\left(T^{*} \mid N\right)=Z_{12}(\gamma \mid N)$.

(4) If $Z_{1}\left(T_{N-1}^{*}, N-1\right) \geq Z_{1}\left(T_{N}^{*}, N\right)$, then the optimum solution, say $\left(T^{*}, N^{*}\right)$, is $\left(T_{N-1}^{*}, N-1\right)$ and $Z^{*}=$ $Z_{1}\left(T^{*}, N^{*}\right)$. Otherwise, $N=N+1$, go to step 2 .

(5) Calculate $\Delta_{2}(N)$ and $\Delta_{3}(N)$.

(1) If $2 A<\Delta_{2}$, then $T^{*}=T_{21}$ and $Z_{2}\left(T_{N}^{*}, N\right)=$ $Z_{2}\left(T^{*} \mid N\right)=Z_{21}\left(T_{21} \mid N\right)$.

(2) If $\Delta_{2} \leq 2 A<\Delta_{3}$, and

(i) $Z_{22}\left(T_{22} \mid N\right) \geq Z_{22}(M-N \mid N)$, then $T^{*}=$ $T_{22}, Z_{2}\left(T_{N}^{*}, N\right)=Z_{2}\left(T^{*} \mid N\right)=Z_{22}\left(T_{22} \mid\right.$ $N)$;

(ii) $Z_{22}\left(T_{22} \mid N\right)<Z_{22}(M-N \mid N)$, then $T^{*}=M-N, Z_{2}\left(T_{N}^{*}, N\right)=Z_{2}\left(T^{*} \mid N\right)=$ $Z_{22}(M-N \mid N)$.

(3) If $2 A \geq \Delta_{3}$, and

(i) $Z_{23}\left(T_{23} \mid N\right) \geq Z_{23}(\gamma \mid N)$, then $T^{*}=T_{23}$, $Z_{2}\left(T_{N}^{*}, N\right)=Z_{2}\left(T^{*} \mid N\right)=Z_{23}\left(T_{23} \mid N\right)$

(ii) $Z_{23}\left(T_{23} \mid N\right)<Z_{23}(\gamma \mid N)$, then $T^{*}=M-$ $N, Z_{2}\left(T_{N}^{*}, N\right)=Z_{2}\left(T^{*} \mid N\right)=Z_{23}(\gamma \mid N)$.
(6) If $Z_{2}\left(T_{N-1}^{*}, N-1\right) \geq Z_{2}\left(T_{N}^{*}, N\right)$, then the optimum solution, say $\left(T^{*}, N^{*}\right)$, is $\left(T_{N-1}^{*}, N-1\right)$ and $Z^{*}=$ $Z_{2}\left(T^{*}, N^{*}\right)$. Otherwise, $N=N+1$, go to step 2 .

(7) Calculate $\Delta_{4}(N)$ and $\Delta_{5}(N)$.

(1) If $2 A<\Delta_{4}$, then $T^{*}=T_{31}$ and $Z_{3}\left(T_{N}^{*}, N\right)=$ $Z_{3}\left(T^{*} \mid N\right)=Z_{31}\left(T_{31} \mid N\right)$.

(2) If $\Delta_{4} \leq 2 A<\Delta_{5}$, and

(i) $Z_{32}\left(T_{32} \mid N\right) \geq Z_{32}(\gamma \mid N)$, then $T^{*}=T_{32}$, $Z_{3}\left(T_{N}^{*}, N\right)=Z_{3}\left(T^{*} \mid N\right)=Z_{32}\left(T_{32} \mid N\right)$

(ii) $Z_{32}\left(T_{32} \mid N\right)<Z_{32}(\gamma \mid N)$, then $T^{*}=\gamma$, $Z_{3}\left(T_{N}^{*}, N\right)=Z_{3}\left(T^{*} \mid N\right)=Z_{32}(\gamma \mid N)$.

(3) If $2 A \geq \Delta_{5}$, and

(i) $Z_{33}\left(T_{33} \mid N\right) \geq Z_{33}(M-N \mid N)$, then $T^{*}=$ $T_{33}, Z_{3}\left(T_{N}^{*}, N\right)=Z_{3}\left(T^{*} \mid N\right)=Z_{33}\left(T_{33} \mid\right.$ $N)$;

(ii) $Z_{22}\left(T_{22} \mid N\right)<Z_{22}(M-N \mid N)$, then $T^{*}=M-N, Z_{3}\left(T_{N}^{*}, N\right)=Z_{3}\left(T^{*} \mid N\right)=$ $Z_{33}(M-N \mid N)$.

(8) If $Z_{3}\left(T_{N-1}^{*}, N-1\right) \geq Z_{3}\left(T_{N}^{*}, N\right)$, then the optimum solution, say $\left(T^{*}, N^{*}\right)$, is $\left(T_{N-1}^{*}, N-1\right)$ and $Z^{*}=$ $Z_{3}\left(T^{*}, N^{*}\right)$. Otherwise, $N=N+1$, go to step 2 .

After obtaining the optimal replenishment cycle $T^{*}$, the optimal order quantity can be determined by (10), which is given that $Q^{*}=D \gamma+(D / \theta)\left[e^{\theta\left(T^{*}-\gamma\right)}-1\right]$.

\section{Special Cases}

In this section, two special cases are discussed (i.e., [12, 42]) and descriptions are made.

Special Case 1 (Ouyang et al. [12]). In this model, they consider an one-level credit financing problem for noninstantaneous deteriorating items with a constant demand, which means, in our model $N \rightarrow 0, r \rightarrow 0$ and $\lim _{r \rightarrow 0} D(N)=\alpha$.

If we set $N \rightarrow 0$ and $r \rightarrow 0$, then for Cases 2 and 3 in our paper, the problem is

(1) for $M \leq \gamma$

$$
\begin{aligned}
\lim _{N \rightarrow 0 r \rightarrow 0} \lim _{21}(T) \\
=(p-c) \alpha \\
-\left[\frac{A}{T}+\frac{h \alpha T}{2}-\frac{p I_{p}}{T} \cdot\left(\frac{\alpha T^{2}}{2}+\alpha T(M-T)\right)\right]
\end{aligned}
$$

$\lim _{N \rightarrow 0 r \rightarrow 0} \lim _{22} Z_{2}(T)$

$$
\begin{aligned}
= & (p-c) \alpha \\
& -\left[\frac{A}{T}+\frac{h \alpha T}{2}+\frac{c I_{c}}{T} \cdot \frac{\alpha(T-M)^{2}}{2}-\frac{p I_{p}}{T} \cdot \frac{\alpha M^{2}}{2}\right]
\end{aligned}
$$


$\lim _{N \rightarrow 0 r \rightarrow 0} \lim _{23}(T)$

$$
\begin{aligned}
=(p-c) \alpha-[ & \left(A+\frac{\left(h+c I_{c}\right) \alpha \gamma^{2}}{2}-c I_{c} M \alpha \gamma\right. \\
& \left.+\frac{c I_{c} M^{2} \alpha}{2}+c \alpha \gamma-\frac{p I_{p} M^{2} \alpha}{2}\right) \times T^{-1} \\
& +\left(\frac{h \gamma \alpha+c I_{c}(\gamma-M) \alpha+c \alpha}{\theta}\right) \\
& \times \frac{e^{\theta(T-\gamma)}-1}{T}+\frac{\left(h+c I_{c}\right) \alpha}{\theta^{2}} \\
& \left.\times \frac{e^{\theta(T-\gamma)}-\theta(T-\gamma)-1}{T}-c \alpha\right], \\
Z_{2}(T)= & \begin{cases}Z_{21}(T) \quad T \leq M \\
Z_{22}(T) \quad & M \leq T \leq \gamma \\
Z_{23}(T) \quad T \geq \gamma,\end{cases}
\end{aligned}
$$

(2) for $M \geq \gamma$

$$
\begin{aligned}
\lim _{N \rightarrow 0} \lim _{r \rightarrow 0} Z_{31} \\
=(p-c) \alpha \\
\quad-\left[\frac{A}{T}+\frac{h \alpha T}{2}-\frac{p I_{p}}{T} \cdot\left(\frac{\alpha T^{2}}{2}+\alpha T(M-T)\right)\right]
\end{aligned}
$$

$$
\lim _{N \rightarrow 0} \lim _{r \rightarrow 0} Z_{32}(T)
$$

$$
\begin{aligned}
& =(p-c) \alpha \\
& -\left[\frac{A}{T}+\frac{h \alpha}{T}\right. \\
& \quad \times\left(\frac{\gamma^{2}}{2}+\frac{\gamma}{\theta}\left(e^{\theta(T-\gamma)}-1\right)\right. \\
& \left.\quad+\frac{1}{\theta^{2}}\left(e^{\theta(T-\gamma)}-\theta(T-\gamma)-1\right)\right) \\
& +\frac{c \alpha}{T}\left(\gamma+\frac{1}{\theta}\left(e^{\theta(T-\gamma)}-1\right)\right) \\
& \left.\quad-c \alpha-\frac{p I_{p}}{T} \cdot\left(\frac{\alpha T^{2}}{2}+\alpha T(M-T)\right)\right],
\end{aligned}
$$

$$
\begin{aligned}
& \lim _{N \rightarrow 0} \lim _{r \rightarrow 0} Z_{33}(T) \\
& =(p-c) \alpha \\
& -\left[\frac{A}{T}+\frac{h \alpha}{T}\right. \\
& \times\left(\frac{\gamma^{2}}{2}+\frac{\gamma}{\theta}\left(e^{\theta(T-\gamma)}-1\right)\right. \\
& \left.+\frac{1}{\theta^{2}}\left(e^{\theta(T-\gamma)}-\theta(T-\gamma)-1\right)\right) \\
& +\frac{c \alpha}{T}\left(\gamma+\frac{1}{\theta}\left(e^{\theta(T-\gamma)}-1\right)\right)-c \alpha \\
& \left.+\frac{c I_{c}}{T}\left(\frac{e^{\theta(T-M)}-1}{\theta^{2}}-\frac{T+M}{\theta}\right)-\frac{p I_{p} M^{2} \alpha}{2 T}\right], \\
& Z_{3}(T)= \begin{cases}Z_{31}(T) & T \leq \gamma \\
Z_{32}(T) & \gamma \leq T \leq M \\
Z_{33}(T) & T \geq M .\end{cases}
\end{aligned}
$$

In this condition, the relevant cost function is the same as the problem in Case 1 (12)-(14) and Case 2 (15)-(17) of Ouyang et al. [12]. So Ouyang et al. [12] is a special case of our model.

Special Case 2(Jaggi et al. [42]). In this model, they consider the tow-level financing problem for items without deterioration and with a credit dependent demand rate, which means that $\theta \rightarrow 0$ and $\gamma \rightarrow \infty$ in our model. If we set $\theta \rightarrow 0$ and $\gamma \rightarrow \infty$, for Cases 1 and 2 in our paper, the problem is

(1) for $M \leq N \leq \gamma$, according to Case 1 in our paper,

$$
\begin{aligned}
& \lim _{\gamma \rightarrow \infty} \lim _{\theta \rightarrow 0} Z_{11}(T, N) \\
& \quad=(p-c) D-\left[\frac{A}{T}+\frac{\left(h+c I_{c}\right) D T}{2}+c I_{c}(N-M) D\right] \\
& \quad \equiv Z_{1}(T, N)
\end{aligned}
$$

(2) for $N \leq M \leq \gamma$, according to Case 2 in our paper,

$$
\begin{aligned}
\lim _{\gamma \rightarrow \infty} & \lim _{\theta \rightarrow 0} Z_{21}(T, N) \\
= & (p-c) D \\
& \quad-\left[\frac{A}{T}+\frac{h D T}{2}-\frac{p I_{p}}{T} \cdot\left(\frac{D T^{2}}{2}+D T(M-T-N)\right)\right] \\
& \equiv Z_{2}(T, N)
\end{aligned}
$$




$$
\begin{aligned}
\lim _{\gamma \rightarrow \infty} \lim _{\theta \rightarrow 0} Z_{22}(T, N) \\
=(p-c) D \\
-\left[\frac{A}{T}+\frac{h D T}{2}+\frac{c I_{c}}{T} \cdot \frac{D(T+N-M)^{2}}{2}\right. \\
\left.\quad \quad-\frac{p I_{p}}{T} \cdot \frac{D(M-N)^{2}}{2}\right] \\
\equiv Z_{3}(T, N),
\end{aligned}
$$

which can be reduced as follows:

$$
Z(T, N)= \begin{cases}Z_{1}(T, N) & M \leq N \leq T+N \\ Z_{2}(T, N) & N \leq T+N \leq M \\ Z_{3}(T, N) & M \leq N \leq T+N .\end{cases}
$$

In this condition, the total average profit functions (66)-(67) are consistent with functions (11), (13), and (15), which are the same as the problem in Jaggi et al. [42]. So Jaggi et al. [42] is also a special case of our model.

\section{Numerical Analysis}

To gain further insights, we conduct the following numerical analysis.

Example 13. We consider the first type of demand rate function: $D(N)=\beta-(\beta-\alpha) e^{-r N}$, in which $\alpha=3600, \beta=$ 10800 and $r=20$. The values of other parameters are $h=4 \$$ per unit year, $p=30 \$$ per unit, $c=20 \$$ per unit, $\theta=0.05$, $\gamma=20 / 365$ year, $M=30 / 365$ year, $A=75 \$, I_{c}=15 \%$ per year, and $I_{p}=20 \%$ per year. According to our analysis of the solution procedure and the algorithm, we run the interactive numerical results with the value of $N=1,2, \ldots, 90$.

There are three conditions for $M=30 / 365$ year and $\gamma=$ 20/365 year.

(a) $N \leq 10 / 365$; (b) $11 / 365 \leq N \leq 30 / 365$; (c) $N \geq$ $31 / 365$.

When $N \leq 10 / 365$, say $N=5 / 365$, we have $\Delta_{4}=159.89$, $\Delta_{5}=258.94$, and $2 A=150<\Delta_{4}$. Hence, $T^{*}=T_{31}=0.0531$ year, and $Z^{*}=Z_{31}\left(T^{*}\right)=53465 \$$.

When $11 / 365 \leq N \leq 30 / 365$, say $N=20 / 365$, we have $\Delta_{2}=63.00, \Delta_{3}=195.31$, and $\Delta_{2}<2 \mathrm{~A}<\Delta_{3}$. Hence, $T^{*}=$ $T_{32}=0.0472$ year, and $Z^{*}=Z_{32}\left(T^{*}\right)=80088 \$$.

When $N \geq 31 / 365$, say $N=45 / 365$, we get $\Delta_{1}=214.13$ and $2 A=150<\Delta_{1}$. Hence, $T^{*}=T_{11}=0.0459$ year, and $Z^{*}=Z_{11}\left(T^{*}\right)=97357 \$$.

Finally, for every constant $N=1 / 365,2 / 365, \ldots, 90 / 365$, we can get the optimal result which is depicted in Figure 11.

From Figure 11 we know that the maximum obtained by the algorithm in this model is indeed the global optimum solution. And the optimal credit offered by the retailer to customers is $N^{*}=69 / 365$ year, the optimal length of replenishment cycle is $T^{*}=16.39 / 365$ year, and the maximum total average profit is $Z^{*}=99607 \$$. Here, we

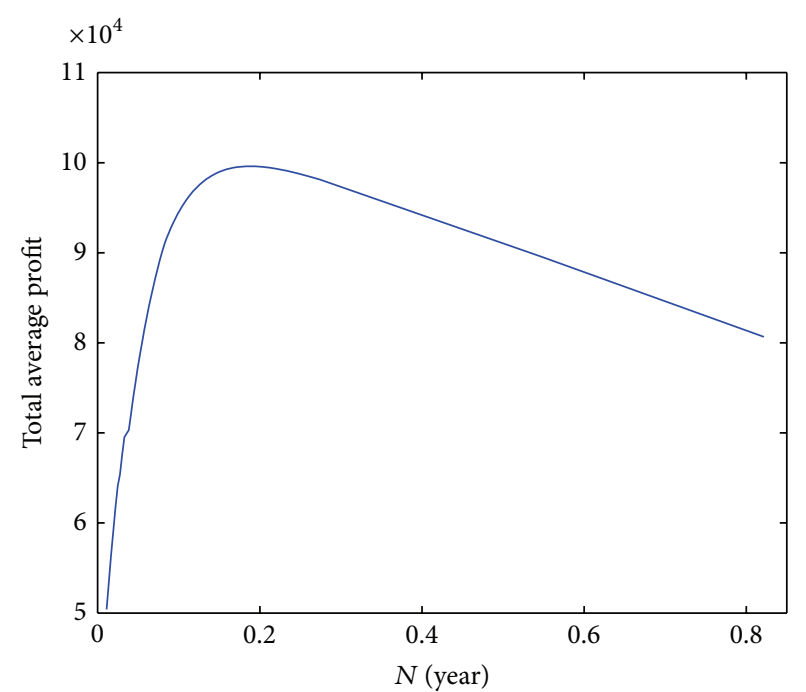

FIGURE 11: Optimal total average profit w.r.t. downstream credit period length of the first type demand.

show that the optimal replenishment cycle length is less than nondeterioration period, and the retailer has to pay for the opportunity cost and not the interest earned.

Example 14. We also consider the first type of demand rate function: $D(N)=\beta-(\beta-\alpha) e^{-r N}$, in which $\alpha=3600$, $\beta=10800$, and $r=20$. The values of other parameters are the same except that $M=70 / 365$ year and $A=150 \$$. Based on the algorithm, the optimal credit offered by the retailer to customers is $N^{*}=67 / 365$ year, the optimal length of replenishment cycle is $T^{*}=22.74 / 365$ year, and the maximum total average profit is $Z^{*}=101720 \$$. In this example, there is interest earned and paid and deterioration cost.

Example 15. Here, we consider the second type of demand rate function: $D(N)=\beta-(\beta-\alpha)(1-r)^{N}$, in which $\alpha=3600$, $\beta=10800$, and $r=0.995$. The values of other parameters are the same to Example 13. The result is shown as Figure 12.

From Figure 12, we know that the global optimum not only exists but also is unique. Based on the algorithm, the optimal credit offered by the retailer to customers is $N^{*}=$ $132 / 365$ year, the optimal length of replenishment cycle is $T^{*}=16.61 / 365$ year, and the maximum total average profit is $Z^{*}=91429 \$$.

6.1. Sensitive Analysis. Here, we consider the first type of demand rate. Initial parameters are the same to these in Example 13. By varying different values for the parameters, we have the results in Table 1.

Comments can be obtained from Table 1 as follows.

(1) It can be observed that as $A$ increases, $T^{*}$ and $Q^{*}$ increases and $Z^{*}$ decreases. The optimal downstream credit $N^{*}$ remains at the threshold. It shows that for a higher ordering cost, the retailer should replenish less frequently and should stock more items at one cycle 


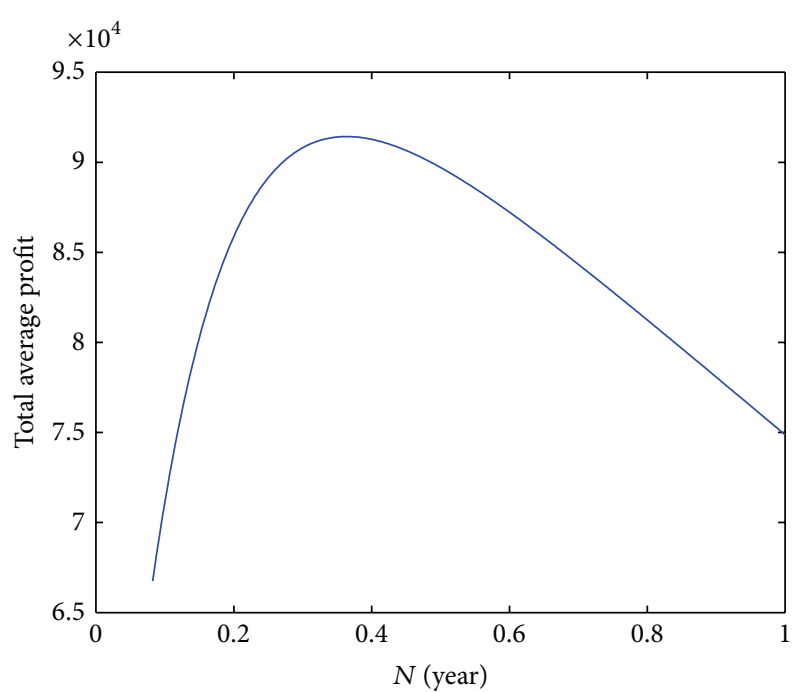

FIGURE 12: Optimal total average profit w.r.t. downstream credit period length of the second type demand.

to avoid the high ordering cost. As a result, for higher ordering cost, the total average profit decreases.

(2) When $h$ increases, $T^{*}, Q^{*}$, and $Z^{*}$ all decrease. The optimal downstream credit $N^{*}$ remains at the threshold. It indicates that for a higher holding cost, the retailer should replenish more often and should reduce the ordering quantity per cycle. Obviously, higher holding cost leads to a lower total average profit.

(3) As the purchasing cost per unit $c$ decreases, $N^{*}, T^{*}$, $Q^{*}$, and $Z^{*}$ all increase, which indicates that if the purchasing cost is lower, the retailer should give more credit to customers to induce the market demand, and set a longer replenishment cycle length, a larger ordering quantity. All these lead to the rise of total average profit.

(4) When selling price $p$ increases, $N^{*}, Q^{*}$, and $Z^{*}$ increase while $T^{*}$ decreases. Hence, for a higher selling price, the retailer should give customers more credit to induce market demand. At the same time, he should shorten the replenishment cycle length and order more items to satisfy the demand. As a result, the retailer can earn more due to a higher selling price.

(5) As the interest rate for the interest charged $I_{c}$ increases, $N^{*}, T^{*}, Q^{*}$, and $Z^{*}$ all decrease. It indicates that to avoid the interest cost, retailer has to shorten the downstream credit, shorten the replenishment cycle length and reduce the ordering quantity.

(6) For a higher changing saturation rate of demand $r$, $N^{*}, T^{*}$, and $Q^{*}$ decrease while $Z^{*}$ increases. It means that the retailer can induce the demand by setting a longer downstream credit. At the same time, to reduce the holding cost, he may order more frequently and reduce the items ordered per cycle. Anyway, the
TABLE 1: Sensitive analysis of Example 13 for parameters $A, h, c, p$, $I_{c}, r, \gamma, M$.

\begin{tabular}{|c|c|c|c|c|c|}
\hline Parameter & & $N^{*}$ (Days) & $T^{*}$ (Days) & $Q^{*}$ (Units) & $Z^{*}(\$)$ \\
\hline \multirow{5}{*}{$A$} & 65 & 69 & 15.26 & 202.3 & 99838 \\
\hline & 70 & 69 & 15.84 & 210.0 & 99720 \\
\hline & 75 & 69 & 16.39 & 217.3 & 99607 \\
\hline & 80 & 69 & 16.94 & 224.6 & 99433 \\
\hline & 85 & 69 & 17.44 & 231.2 & 99391 \\
\hline \multirow{5}{*}{$h$} & 3.6 & 69 & 16.86 & 223.6 & 99704 \\
\hline & 3.8 & 69 & 16.61 & 220.2 & 99655 \\
\hline & 4.0 & 69 & 16.39 & 217.3 & 99607 \\
\hline & 4.2 & 69 & 16.17 & 214.4 & 99560 \\
\hline & 4.4 & 69 & 15.95 & 211.5 & 99513 \\
\hline \multirow{5}{*}{$c$} & 16 & 79 & 17.08 & 234.0 & 143216 \\
\hline & 18 & 74 & 16.72 & 225.4 & 121352 \\
\hline & 20 & 69 & 16.39 & 217.3 & 99607 \\
\hline & 22 & 63 & 16.10 & 209.1 & 78019 \\
\hline & 24 & 56 & 15.84 & 200.7 & 56654 \\
\hline \multirow{5}{*}{$p$} & 26 & 59 & 16.46 & 210.8 & 57267 \\
\hline & 28 & 64 & 16.43 & 214.2 & 78381 \\
\hline & 30 & 69 & 16.39 & 217.3 & 99607 \\
\hline & 32 & 72 & 16.35 & 219.0 & 120903 \\
\hline & 34 & 75 & 16.35 & 221.1 & 142246 \\
\hline \multirow{5}{*}{$I_{c}$} & 0.11 & 75 & 17.37 & 234.9 & 100769 \\
\hline & 0.13 & 71 & 16.86 & 225.1 & 100169 \\
\hline & 0.15 & 69 & 16.39 & 217.3 & 99607 \\
\hline & 0.17 & 66 & 15.95 & 209.3 & 99077 \\
\hline & 0.19 & 64 & 15.55 & 202.7 & 98575 \\
\hline \multirow{5}{*}{$r$} & 16 & 81 & 16.43 & 226.5 & 98158 \\
\hline & 18 & 74 & 16.39 & 221.0 & 98951 \\
\hline & 20 & 69 & 16.39 & 217.3 & 99607 \\
\hline & 22 & 64 & 16.39 & 213.6 & 100160 \\
\hline & 24 & 60 & 16.35 & 210.1 & 100633 \\
\hline \multirow{5}{*}{$\gamma$} & 10 & 70 & 15.70 & 208.9 & 99573 \\
\hline & 15 & 69 & 16.24 & 215.4 & 99599 \\
\hline & 20 & 69 & 16.39 & 217.3 & 99607 \\
\hline & 25 & 69 & 16.39 & 217.3 & 99607 \\
\hline & 30 & 69 & 16.39 & 217.3 & 99607 \\
\hline \multirow{5}{*}{$M$} & 26 & 69 & 16.39 & 217.3 & 99257 \\
\hline & 28 & 69 & 16.39 & 217.3 & 99432 \\
\hline & 30 & 69 & 16.39 & 217.3 & 99607 \\
\hline & 32 & 69 & 16.39 & 217.3 & 99782 \\
\hline & 34 & 69 & 16.39 & 217.3 & 99957 \\
\hline
\end{tabular}

increase of the saturation rate brings more profit to the retailer.

(7) As the deterioration starting point $\gamma$ increases, $T^{*}, Q^{*}$, and $Z^{*}$ increase. It shows that deterioration can cause cost for retailer. If the items are more unwilling to deteriorate, he can earn more by ordering less often and ordering more items per cycle. 
TABLE 2: Sensitive analysis of Example 14 for parameters $I_{p}$ and $\theta$.

\begin{tabular}{cccccc}
\hline Parameter & & $N^{*}$ (Days) & $T^{*}$ (Days) & $Q^{*}$ (Units) & $Z^{*}(\$)$ \\
\hline \multirow{4}{*}{$I_{p}$} & 0.16 & 69 & 22.78 & 669.2 & 101715 \\
& 0.18 & 68 & 22.78 & 668.9 & 101717 \\
& 0.20 & 67 & 22.74 & 667.4 & 101719 \\
& 0.22 & 65 & 22.60 & 662.5 & 101726 \\
$\theta$ & 0.24 & 62 & 22.12 & 647.1 & 101743 \\
\hline \multirow{4}{*}{0} & 0.03 & 67 & 22.89 & 671.8 & 101721 \\
& 0.04 & 67 & 22.81 & 669.4 & 101720 \\
& 0.05 & 67 & 22.74 & 667.4 & 101719 \\
& 0.06 & 67 & 22.67 & 665.3 & 101718 \\
& 0.07 & 67 & 22.59 & 663.0 & 101718 \\
\hline
\end{tabular}

(8) If $M$ increases, $N^{*}, T^{*}$, and $Q^{*}$ stay at the same threshold while $Z^{*}$ increases. Obviously, if the supplier offers the retailer a longer credit, he can earn more from the interest earned.

(9) Because there is no deterioration cost and interest earned in Example 13, so there is no influence of parameter $I_{p}$ and $\theta$.

To better illustrate the sensitive of parameter $I_{p}$ and $\theta$, we make another sensitive analysis based on Example 14. The results are shown as Table 2.

We also conclude that,

(1) As the interest earned rate $I_{p}$ increases, $N^{*}, T^{*}$, and $Q^{*}$ decrease while $Z^{*}$ increases. It means that the retailer should shorten the downstream credit length and the replenishment cycle length, and reduce the ordering quantity per cycle.

(2) As the deterioration rate $\theta$ increases, $T^{*}, Q^{*}$, and $Z^{*}$ decrease. It shows that to avoid the deterioration cost, the retailer tries to keep a lower stock level and orders more frequently.

\section{Conclusions and Future Research}

Financing tools play a more and more important role in business today, which provide us with a new method to study the inventory problems. In the inventory problems, credit can have significant influence on the inventory decisions, that is, ordering quantity and ordering cycle length. In this study, we propose an EOQ model of a kind of noninstantaneous deterioration items with two-level credit and creditdependent demand rate. The purpose of this research is to help the retailer determine the optimal replenishment cycle length, optimal ordering quantity, and optimal credit period offered to customers under different situations. It is also a general frame work for many researches, such as Ouyang et al. [12] and Jaggi et al. [42].

In future research, our model can be extended to more general supply chain structures, for example, decentralized and centralized supply chain. Also, we can regard the price as a decision variable, or we can set assumptions for partial credit and advanced payment discounts.

\section{Appendices}

\section{A.}

Proof of Lemma 1, Part (a). Motivated by (43), we define a new function $F_{1}(x)$ as follows:

$$
\begin{aligned}
F_{1}(x)= & {\left[A+\frac{\left(h+c I_{c}\right) D \gamma^{2}}{2}+c D \gamma+c I_{c}(N-M) D \gamma\right] } \\
& -\left[\frac{\left(h+c I_{c}\right) D \gamma}{\theta}+\frac{c+c I_{c}(N-M)}{\theta} D\right] \\
& \times\left(\theta T e^{\theta(x-\gamma)}-e^{\theta(x-\gamma)}+1\right) \\
& -\frac{\left(h+c I_{c}\right) D}{\theta^{2}}\left(\theta e^{\theta(x-\gamma)}-e^{\theta(x-\gamma)}+1-\theta \gamma\right),
\end{aligned}
$$

for $x \in[\gamma,+\infty)$.

Since the first derivative of $F_{1}(x)$ with respect to $x \in$ $[\gamma,+\infty)$ is

$$
\begin{aligned}
F^{\prime}(x)= & -\left[h \theta \gamma+c \theta I_{c}(N-M)+c \theta I_{c} \gamma+c \theta+h+c I_{c}\right] \\
& \times D x e^{\theta(x-\gamma)}<0,
\end{aligned}
$$

we obtain that $F_{1}(x)$ is a strict decreasing function of $x$ in the interval $[\gamma,+\infty)$. Moreover, we have $\left.F_{1}(x)\right|_{x \rightarrow \infty}=-\infty$, and

$$
\left.F_{1}(x)\right|_{x \rightarrow \gamma}=A-\frac{\left(h+c I_{c}\right) D \gamma^{2}}{2} .
$$

Therefore, if $2 A \geq\left(h+c I_{c}\right) D \gamma^{2}$, then $\left.F_{1}(x)\right|_{x \rightarrow \gamma} \geq 0$. According to the intermediate value theorem, there exists a unique $T_{12} \in[\gamma,+\infty)$ such that $F_{1}\left(T_{12}\right)=0$.

Proof of Lemma 1, Part (b). If $0<2 A<\left(h+c I_{c}\right) D \gamma^{2}$, then from (A.3), $F_{1}(\gamma)<0$. Since $F_{1}(x)$ is a strict decreasing function of $x$ in the interval $[\gamma,+\infty)$; thus, there is no value of $T \in[\gamma,+\infty)$ such that $F_{1}(T)=0$.

Proof of Lemma 2, Part (a). When $2 A \geq\left(h+c I_{c}\right) D \gamma^{2}, T_{12}$ is the unique solution of (43) from Lemma $1(\mathrm{a})$. Taking the second derivative of $Z_{12}(T)$ with respect to $T$ and finding the value of the function at the point $T_{12}$, we obtain

$$
\begin{aligned}
& \frac{\partial^{2} Z_{12}}{T^{2}} \\
& =-\frac{\left[h \theta \gamma+c I_{c}(N-M)+c \theta I_{c} \gamma+c \theta+h+c I_{c}\right] D e^{\theta\left(T_{12}-\gamma\right)}}{T_{12}} \\
& <0 .
\end{aligned}
$$

Thus, $T_{12}$ is the global maximum point of $Z_{12}(T)$. 
Proof of Lemma 2, Part (b). From the proof of Lemma 1(b), we know that if $0<2 A \leq\left(h+c I_{c}\right) D \gamma^{2}$, then $F_{1}(x)<0$, for all $x \in[\gamma,+\infty)$. Thus we have

$$
\begin{aligned}
\frac{\partial Z_{12}}{\partial T} & \\
= & \frac{\left[A+\left(\left(h+c I_{c}\right) D \gamma^{2} / 2\right)+c D \gamma+c I_{c}(N-M) D \gamma\right]}{T^{2}} \\
& -\left[\left(\frac{\left(h+c I_{c}\right) D \gamma}{\theta}\right)+\left(\frac{\left(c+c I_{c}(N-M)\right)}{\theta}\right) D\right] \\
& \times\left(\theta T e^{\theta(T-\gamma)}-e^{\theta(T-\gamma)}+1\right) \times\left(T^{2}\right)^{-1} \\
& -\frac{\left(\left(h+c I_{c}\right) D / \theta^{2}\right)\left(\theta e^{\theta(T-\gamma)}-e^{\theta(T-\gamma)}+1-\theta \gamma\right)}{T^{2}} \\
= & \frac{F_{1}(T)}{T^{2}}<0,
\end{aligned}
$$

for all $T \in[\gamma,+\infty)$, which implies that $Z_{12}(T)$ is a strict decreasing function of $T \in[\gamma,+\infty)$. So, $Z_{12}(T)$ has a maximum value at the boundary point $T=\gamma$.

\section{B.}

Proof of Lemma 4, Part (a). Motivated by (53), we define a new function $F_{2}(x)$ as follows:

$$
\begin{aligned}
F_{2}(x)= & {\left[A+\frac{\left(h+c I_{c}\right) D \gamma^{2}}{2}-c I_{c}(M-N) D \gamma\right.} \\
& \left.+\frac{c I_{c}(M-N)^{2} D}{2}+c D \gamma-\frac{p I_{p}(M-N)^{2} D}{2}\right] \\
& -\left[\frac{h \gamma D+c I_{c}(\gamma-M+N) D+c D}{\theta}\right] \\
& \times\left(\theta T e^{\theta(x-\gamma)}-e^{\theta(x-\gamma)}+1\right) \\
& -\frac{\left(h+c I_{c}\right) D}{\theta^{2}}\left(\theta e^{\theta(x-\gamma)}-e^{\theta(x-\gamma)}+1-\theta \gamma\right) . \\
& \text { for } x \in[\gamma,+\infty) .
\end{aligned}
$$

Since the first derivative of $F_{2}(x)$ with respect to $x \in$ $[\gamma,+\infty)$ is

$$
\begin{aligned}
F_{2}^{\prime}(x)= & -\left[h \theta \gamma+c \theta I_{c}(\gamma+N-M)+c \theta+h+c I_{c}\right] \\
& \times D x e^{\theta(x-\gamma)}<0,
\end{aligned}
$$

we obtain that $F_{2}(x)$ is a strict decreasing function of $x$ in the interval $[\gamma,+\infty)$. Moreover, we have $\left.F_{2}(x)\right|_{x \rightarrow \infty}=-\infty$, and

$$
\left.F_{2}(x)\right|_{x \rightarrow \gamma}=A-\frac{\left(h+c I_{c}\right) \gamma^{2} D-\left(c I_{c}-p I_{p}\right)(M-N)^{2} D}{2} \text {. }
$$

Therefore, if $2 A \geq\left(h+c I_{c}\right) \gamma^{2} D-\left(c I_{c}-p I_{p}\right)(M-N)^{2} D$, then $\left.F_{2}(x)\right|_{x \rightarrow \gamma} \geq 0$. According to the intermediate value theorem, there exists a unique $T_{23} \in[\gamma,+\infty)$ such that $F_{2}\left(T_{23}\right)=0$.

Proof of Lemma 4, part (b). If $2 A<\left(h+c I_{c}\right) \gamma^{2} D-\left(c I_{c}-\right.$ $\left.p I_{p}\right)(M-N)^{2} D$, then from (A.3), $F_{2}(\gamma)<0$. Since $F_{2}(x)$ is a strict decreasing function of $x$ in the interval $[\gamma,+\infty)$; thus, there is no value of $T \in[\gamma,+\infty)$ such that $F_{2}(T)=0$.

Proof of Lemma 5, Part (a). When $2 A \geq\left(h+c I_{c}\right) \gamma^{2} D-\left(c I_{c}-\right.$ $\left.p I_{p}\right)(M-N)^{2} D, T_{23}$ is the unique solution of (53) from Lemma 4(a). Taking the second derivative of $Z_{23}(T)$ with respect to $T$ and finding the value of the function at the point $T_{23}$, we obtain

$$
\begin{aligned}
& \frac{\partial^{2} Z_{23}}{T^{2}} \\
& \quad=-\frac{\left[h \theta \gamma+c I_{c}(N-M)+c \theta I_{c} \gamma+c \theta+h+c I_{c}\right] D e^{\theta\left(T_{23}-\gamma\right)}}{T_{23}} \\
& \quad<0 .
\end{aligned}
$$

Thus, $T_{23}$ is the global minimum point of $Z_{23}(T)$.

Proof of Lemma 5, Part (b). From the proof of Lemma 4(b), we know that if $0<2 A<\left(h+c I_{c}\right) \gamma^{2} D-\left(c I_{c}-p I_{p}\right)(M-N)^{2} D$, then $F_{2}(x)>0$, for all $x \in[\gamma,+\infty)$. Thus we have

$$
\begin{aligned}
\frac{\partial Z_{23}}{\partial T} & \\
= & {\left[A+\frac{\left(h+c I_{c}\right) D \gamma^{2}}{2}-c I_{c}(M-N) D \gamma\right.} \\
& \left.+\frac{c I_{c}(M-N)^{2} D}{2}+c D \gamma-\frac{p I_{p}(M-N)^{2} D}{2}\right] \times\left(T^{2}\right)^{-1} \\
& -\left[\frac{h \gamma D+c I_{c}(\gamma-M+N) D+c D}{\theta}\right] \\
& \times\left(\theta T e^{\theta(x-\gamma)}-e^{\theta(x-\gamma)}+1\right) \times\left(T^{2}\right)^{-1} \\
& -\frac{\left(\left(h+c I_{c}\right) D / \theta^{2}\right)\left(\theta e^{\theta(x-\gamma)}-e^{\theta(x-\gamma)}+1-\theta \gamma\right)}{T^{2}} \\
= & \frac{F_{2}(T)}{T^{2}<0, \quad \forall T \in[\gamma,+\infty),}
\end{aligned}
$$

which implies that $Z_{23}(T)$ is a strict decreasing function of $T \in[\gamma,+\infty)$. So, $Z_{23}(T)$ has a maximum value at the boundary point $T=\gamma$. 
C.

Proof of Lemma 7, Part (a). Motivated by (60), we define a new function $F_{3}(x)$ as follows:

$$
\begin{aligned}
F_{3}(x)= & \left(A+\frac{h D \gamma^{2}}{2}+c D \gamma\right)-\left(\frac{h D \gamma+c D}{\theta}\right) \\
& \times\left(\theta T e^{\theta(T-\gamma)}-e^{\theta(T-\gamma)}+1\right) \\
& -\frac{h D}{\theta^{2}}\left(\theta T e^{\theta(T-\gamma)}-e^{\theta(T-\gamma)}+1-\theta \gamma\right)-\frac{p I_{p} D T^{2}}{2} \\
& \text { for } x \in[\gamma, M-N] .
\end{aligned}
$$

Since the first derivative of $F_{3}(x)$ with respect to $x \in[\gamma, M-$ $N]$ is

$$
F_{3}^{\prime}(x)=-\left(\frac{h D \gamma+c D}{\theta}+\frac{h D}{\theta^{2}}\right) \theta T e^{\theta(T-\gamma)}-p I_{p} D T<0,
$$

we obtain that $F_{3}(x)$ is a strict decreasing function of $x$ in the interval $[\gamma, M-N]$. Moreover,

$$
\begin{gathered}
\left.F_{3}(x)\right|_{x \rightarrow \gamma}=A-\frac{h D \gamma^{2}}{2}+\frac{p I_{p} D}{2}, \\
\left.F_{3}(x)\right|_{x \rightarrow M-N} \\
=\left(A+\frac{h D \gamma^{2}}{2}+c D \gamma\right)-\left(\frac{h D \gamma+c D}{\theta}+\frac{h D}{\theta^{2}}\right) \\
\times\left[\theta(M-N) e^{\theta(M-N-\gamma)}-e^{\theta(M-N-\gamma)}+1\right] \\
+\frac{h D \gamma}{\theta}-\frac{p I_{p} D(M-N)^{2}}{2} .
\end{gathered}
$$

According to the intermediate value theorem, when $\Delta_{4} \leq$ $2 A \leq \Delta_{5}$, then $\left.F_{3}(x)\right|_{x \rightarrow M-N} \leq 0$ and $\left.F_{3}(x)\right|_{x \rightarrow \gamma} \geq 0$, so there exists a unique $T_{32} \in[\gamma, M-N]$ such that $F_{3}\left(T_{32}\right)=0$.

Proof of Lemma 7, Part (b). If $2 A<\Delta_{4}$ or $2 A>\Delta_{5}$, then $\left.F_{3}(x)\right|_{x \rightarrow \gamma}<0$ or $\left.F_{3}(x)\right|_{x \rightarrow M-N}>0$. Since $F_{3}(x)$ is a strict decreasing function of $x$ in the interval $[\gamma, M-N]$. Thus, there is no value of $T \in[\gamma, M-N]$ such that $F_{3}(T)=0$.

Proof of Lemma 8, Part (a). When $\Delta_{4} \leq 2 A \leq \Delta_{5}, T_{32}$ is the unique solution of (60) from Lemma 7 (a). Taking the second derivative of $Z_{32}(T)$ with respect to $T$ and finding the value of the function at the point $T_{32}$, we obtain

$$
\begin{aligned}
& \left.\frac{\partial^{2} Z_{32}(T)}{\partial T^{2}}\right|_{T=T_{32}} \\
& \quad=-\frac{\left((h D \gamma+c D) / \theta+h D / \theta^{2}\right) \theta e^{\theta\left(T_{32}-\gamma\right)}}{T_{32}}-\frac{p I_{p} D}{T_{32}} \\
& \quad<0 .
\end{aligned}
$$

Thus, $T_{32}$ is the global maximum point of $Z_{32}(T)$.
Proof of Lemma 8, Part (b). From the proof of Lemma 7(b), we know that if $2 A<\Delta_{4}$, then $F_{3}(x)<0$ for all $x \in[\gamma, M-$ $N]$. Thus, we have

$$
\begin{aligned}
\frac{\partial Z_{32}}{\partial T}= & \frac{\left(A+h D \gamma^{2} / 2+c D \gamma\right)}{T^{2}} \\
& -\frac{((h D \gamma+c D) / \theta)\left(\theta T e^{\theta(T-\gamma)}-e^{\theta(T-\gamma)}+1\right)}{T^{2}} \\
& -\frac{\left(h D / \theta^{2}\right)\left(\theta T e^{\theta(T-\gamma)}-e^{\theta(T-\gamma)}+1-\theta \gamma\right)}{T^{2}}-\frac{p I_{p} D}{2} \\
= & \frac{F_{3}(T)}{T^{2}}<0, \quad \forall T \in[\gamma, M-N],
\end{aligned}
$$

which implies that $Z_{32}(T)$ is a strict decreasing function of $T \in[\gamma, M-N]$. So, $\max Z_{32}(T)=Z_{32}(\gamma)$.

Proof of Lemma 8, Part (c). From the proof of Lemma 7(b), we know that if $2 A>\Delta_{5}$, then $F_{3}(x)>0$ for all $x \in$ $[\gamma, M-N]$. Thus, we have

$$
\begin{aligned}
\frac{\partial Z_{32}}{\partial T}= & \frac{\left(A+h D \gamma^{2} / 2+c D \gamma\right)}{T^{2}} \\
& -\frac{((h D \gamma+c D) / \theta)\left(\theta T e^{\theta(T-\gamma)}-e^{\theta(T-\gamma)}+1\right)}{T^{2}} \\
& -\frac{\left(h D / \theta^{2}\right)\left(\theta T e^{\theta(T-\gamma)}-e^{\theta(T-\gamma)}+1-\theta \gamma\right)}{T^{2}}-\frac{p I_{p} D}{2} \\
= & \frac{F_{3}(T)}{T^{2}}<0, \quad \forall T \in[\gamma, M-N],
\end{aligned}
$$

which implies that $Z_{23}(T)$ is a strict decreasing function of $T \in[\gamma, M-N]$. So, $\max Z_{32}(T)=Z_{32}(M-N)$.

D.

Proof of Lemma 9, Part (a). Motivated by (53), we define a new function $F_{2}(x)$ as follows:

$$
\begin{aligned}
& F_{4}(x) \\
& =\left(A+\frac{h D \gamma^{2}}{2}+c D \gamma-c I_{c}(M-N)-\frac{p I_{p}(M-N)^{2} D}{2}\right) \\
& -\left(\frac{h D \gamma+c D}{\theta}\right)\left(\theta T e^{\theta(T-\gamma)}-e^{\theta(T-\gamma)}+1\right) \\
& -\frac{h D}{\theta^{2}}\left(\theta T e^{\theta(T-\gamma)}-e^{\theta(T-\gamma)}+1-\theta \gamma\right) \\
& -\frac{c I_{c}}{\theta^{2}}\left(\theta T e^{\theta(T-M+N)}-e^{\theta(T-M+N)}+1\right)
\end{aligned}
$$$$
\text { for } x \in[M-N,+\infty) \text {. }
$$ 
Since the first derivative of $F_{4}(x)$ with respect to $x \in[M-$ $N,+\infty)$ is

$$
\begin{aligned}
F_{4}^{\prime}(x)= & -\left(\frac{h D \gamma+c D}{\theta}+\frac{h D}{\theta^{2}}\right) \theta T e^{\theta(T-\gamma)} \\
& -\frac{c I_{c}}{\theta} T e^{\theta(T-M+N)}<0
\end{aligned}
$$

we obtain that $F_{4}(x)$ is a strict decreasing function of $x$ in the interval $[M-N,+\infty)$. Moreover, we have $\left.F_{4}(x)\right|_{x \rightarrow \infty}=-\infty$, and

$$
\begin{aligned}
\left.F(x)\right|_{x \rightarrow M-N}= & \left(A+\frac{h D \gamma^{2}}{2}+c D \gamma\right)-\left(\frac{h D \gamma+c D}{\theta}+\frac{h D}{\theta^{2}}\right) \\
& \times\left[\theta(M-N) e^{\theta(M-N-\gamma)}-e^{\theta(M-N-\gamma)}+1\right] \\
& +\frac{h D \gamma}{\theta}+\frac{p I_{p}(M-N)^{2} D}{2} .
\end{aligned}
$$

Therefore, if $2 A \geq \Delta_{5}$, then $\left.F_{4}(x)\right|_{x \rightarrow M-N} \geq 0$. According to the intermediate value theorem, there exists a unique $T_{33} \in$ $[M-N,+\infty)$ such that $F_{4}\left(T_{33}\right)=0$.

Proof of Lemma 9, Part (b). If $0<2 A<\Delta_{5}$, then from (D.3) $F_{4}(M-N)<0$. Since $F_{4}(x)$ is a strict decreasing function of $x$ in the interval $[M-N,+\infty)$. Thus, there is no value of $T \in[M-N,+\infty)$ such that $F_{4}(T)=0$.

Proof of Lemma 10, Part (a). When $2 A \geq \Delta_{5}, T_{33}$ is the unique solution of (63) from Lemma 9 (a). Taking the second derivative of $Z_{33}(T)$ with respect to $T$ and finding the value of the function at the point $T_{33}$, we obtain

$$
\begin{aligned}
& \frac{\partial^{2} Z_{33}}{T^{2}} \\
& =-\frac{\left((h D \gamma+c D) / \theta+h D / \theta^{2}\right) \theta e^{\theta(T-\gamma)}}{T_{33}}-\frac{c I_{c} e^{\theta(T-M+N)}}{\theta T_{33}} \\
& <0 .
\end{aligned}
$$

Thus, $T_{33}$ is the global maximum point of $Z_{33}(T)$.

Proof of Lemma 10, Part (b). From the proof of Lemma 9(b), we know that if $0<2 A<\Delta_{5}$, then $F_{4}(x)<0$, for all $x \in$ $[M-N,+\infty)$. Thus we have

$$
\begin{aligned}
\frac{\partial Z_{33}}{\partial T} & \\
= & \frac{\left(A+h D \gamma^{2} / 2+c D \gamma-c I_{c}(M-N)-p I_{p}(M-N)^{2} D / 2\right)}{T^{2}} \\
& -\frac{((h D \gamma+c D) / \theta)\left(\theta T e^{\theta(T-\gamma)}-e^{\theta(T-\gamma)}+1\right)}{T^{2}} \\
& -\frac{\left(h D / \theta^{2}\right)\left(\theta T e^{\theta(T-\gamma)}-e^{\theta(T-\gamma)}+1-\theta \gamma\right)}{T^{2}}
\end{aligned}
$$

$$
\begin{aligned}
& -\frac{\left(c I_{c} / \theta^{2}\right)\left(\theta T e^{\theta(T-M+N)}-e^{\theta(T-M+N)}+1\right)}{T^{2}} \\
= & \frac{F_{4}(T)}{T^{2}}<0, \quad \forall T \in[M-N,+\infty),
\end{aligned}
$$

which implies that $Z_{33}(T)$ is a strict decreasing function of $T \in[M-N,+\infty) . Z_{23}(T)$ has a maximum value at the boundary point $T=M-N$ for $T \in[M-N,+\infty)$.

\section{Acknowledgments}

The authors thank the valuable comments of the reviewers for an earlier version of this paper. Their comments have significantly improved the paper. This work is supported by the National Natural Science Foundation of China (nos. 71001025 and 71371003). Also, this research is partly supported by the Program for New Century Excellent Talents in the University (no. NCET-10-0327) and the Ministry of Education of China: Grant-in-aid for Humanity and Social Science Research (no. 11YJCZH139).

\section{References}

[1] N. H. Shah, H. N. Soni, and K. A. Patel, "Optimizing inventory and marketing policy for non-instantaneous deteriorating items with generalized type deterioration and holding cost rates," Omega, vol. 41, no. 2, pp. 421-430, 2013.

[2] P. M. Ghare and G. F. Schrader, "A model for exponentially decaying inventory," The Journal of Industrial Engineering, vol. 5, no. 14, pp. 238-243, 1963.

[3] R. P. Covert and G. C. Philip, "An EOQ model for items with Weibull distribution deterioration," AIIE Transactions, vol. 5, no. 4, pp. 323-326, 1973.

[4] G. C. Philip, "A generalized EOQ model for items with Weibull distribution deterioration," AIIE Transactions, vol. 6, no. 2, pp. 159-162, 1974.

[5] Y. He and J. He, "A production model for deteriorating inventory items with production disruptions," Discrete Dynamics in Nature and Society, vol. 2010, Article ID 189017, 14 pages, 2010.

[6] Y. He, S. Wang, and K. K. Lai, "An optimal production-inventory model for deteriorating items with multiple-market demand," European Journal of Operational Research, vol. 203, no. 3, pp. 593-600, 2010.

[7] H. L. Yang, J. T. Teng, and M. S. Chern, "An inventory model under inflation for deteriorating items with stock-dependent consumption rate and partial backlogging shortages," International Journal of Production Economics, vol. 123, no. 1, pp. 8-19, 2010.

[8] Y. He and S. Y. Wang, "Analysis of production-inventory system for deteriorating items with demand disruption," International Journal of Production Research, vol. 50, no. 16, pp. 4580-4592, 2012.

[9] S. K. Goyal and B. C. Giri, "Recent trends in modeling of deteriorating inventory," European Journal of Operational Research, vol. 134, no. 1, pp. 1-16, 2001.

[10] R. Li, H. Lan, and J. Mawhinney, "A review on deteriorating inventory study," Journal of Service Science and Management, vol. 3, no. 1, pp. 117-129, 2010. 
[11] K. S. Wu, L. Y. Ouyang, and C. T. Yang, "An optimal replenishment policy for non-instantaneous deteriorating items with stock-dependent demand and partial backlogging," International Journal of Production Economics, vol. 101, no. 2, pp. 369384, 2006.

[12] L. Ouyang, K. Wu, and C. Yang, "A study on an inventory model for non-instantaneous deteriorating items with permissible delay in payments," Computers and Industrial Engineering, vol. 51, no. 4, pp. 637-651, 2006.

[13] L. Ouyang, K. Wu, and C. Yang, "Retailer's ordering policy for non-instantaneous deteriorating items with quantity discount, stock-dependent demand and stochastic backorder rate," Journal of the Chinese Institute of Industrial Engineers, vol. 25, no. 1, pp. 62-72, 2008.

[14] C. Sugapriya and K. Jeyaraman, "Determining a common production cycle time for an EPQ model with non-instantaneous deteriorating items allowing price discount using permissible delay in payments," ARPN Journal of Engineering and Applied Sciences, vol. 3, no. 2, pp. 26-30, 2008.

[15] K. J. Chung, "A complete proof on the solution procedure for non-instantaneous deteriorating items with permissible delay in payment," Computers and Industrial Engineering, vol. 56, no. 1, pp. 267-273, 2009.

[16] C. T. Yang, L. Y. Ouyang, and H. Wu, "Retailer's optimal pricing and ordering policies for non-instantaneous deteriorating items with price-dependent demand and partial backlogging," Mathematical Problems in Engineering, vol. 2009, Article ID 198305, 18 pages, 2009.

[17] K. S. Wu, L.Y. Ouyang, and C. T. Yang, "Coordinating replenishment and pricing policies for non-instantaneous deteriorating items with price-sensitive demand," International Journal of Systems Science, vol. 40, no. 12, pp. 1273-1281, 2009.

[18] K. V. Geetha and R. Uthayakumar, "Economic design of an inventory policy for non-instantaneous deteriorating items under permissible delay in payments," Journal of Computational and Applied Mathematics, vol. 233, no. 10, pp. 2492-2505, 2010.

[19] S. R. Singh, R. Kumari, and N. Kumar, "Replenishment policy for non-instantaneous deteriorating items with stockdependent demand and partial back logging with two-storage facilities under inflation," International Journal of Operations Research and Optimization, vol. 1, no. 1, pp. 161-179, 2010.

[20] J. H. Chang and F. W. Lin, "A partial backlogging inventory model for non-instantaneous deteriorating items with stockdependent consumption rate under inflation," Yugoslav Journal of Operations Research, vol. 20, no. 1, pp. 35-54, 2010.

[21] C. Chang, J. Teng, and S. K. Goyal, "Optimal replenishment policies for non-instantaneous deteriorating items with stockdependent demand," International Journal of Production Economics, vol. 123, no. 1, pp. 62-68, 2010.

[22] R. Maihami and I. Nakhai Kamalabadi, "Joint pricing and inventory control for non-instantaneous deteriorating items with partial backlogging and time and price dependent demand," International Journal of Production Economics, vol. 136, no. 1, pp. 116-122, 2012.

[23] S. K. Goyal, "Economic order quantity under conditions of permissible delay in payments," Journal of the Operational Research Society, vol. 36, no. 4, pp. 335-338, 1985.

[24] S. P. Aggarwal and C. K. Jaggi, "Ordering policies of deteriorating items under permissible delay in payments," The Journal of the Operational Research Society, vol. 46, no. 5, pp. 658-662, 1995.
[25] A. M. M. Jamal, B. R. Sarker, and S. Wang, "An ordering policy for deteriorating items with allowable shortage and permissible delay in payment," Journal of the Operational Research Society, vol. 48, no. 8, pp. 826-833, 1997.

[26] H. Chang and C. Dye, "An inventory model for deteriorating items with partial backlogging and permissible delay in payments," International Journal of Systems Science, vol. 32, no. 3, pp. 345-352, 2001.

[27] J.-T. Teng, "On the economic order quantity under conditions of permissible delay in payments," Journal of the Operational Research Society, vol. 53, no. 8, pp. 915-918, 2002.

[28] K. J. Chung, S. K. Goyal, and Y. Huang, "The optimal inventory policies under permissible delay in payments depending on the ordering quantity," International Journal of Production Economics, vol. 95, no. 2, pp. 203-213, 2005.

[29] J. T. Teng, C. T. Chang, and S. K. Goyal, "Optimal pricing and ordering policy under permissible delay in payments," International Journal of Production Economics, vol. 97, no. 2, pp. 121-129, 2005.

[30] M. Y. Jaber and I. H. Osman, "Coordinating a two-level supply chain with delay in payments and profit sharing," Computers and Industrial Engineering, vol. 50, no. 4, pp. 385-400, 2006.

[31] K. J. Chung and J. Liao, "The optimal ordering policy in a DCF analysis for deteriorating items when trade credit depends on the order quantity," International Journal of Production Economics, vol. 100, no. 1, pp. 116-130, 2006.

[32] Y.-F. Huang, "Optimal retailer's ordering policies in the EOQ model under trade credit financing," Journal of the Operational Research Society, vol. 54, no. 9, pp. 1011-1015, 2003.

[33] C. Ho, L. Ouyang, and C. Su, "Optimal pricing, shipment and payment policy for an integrated supplier-buyer inventory model with two-part trade credit," European Journal of Operational Research, vol. 187, no. 2, pp. 496-510, 2008.

[34] J. Liao, "An EOQ model with noninstantaneous receipt and exponentially deteriorating items under two-level trade credit," International Journal of Production Economics, vol. 113, no. 2, pp. 852-861, 2008.

[35] A. Thangam and R. Uthayakumar, "Two-echelon trade credit financing for perishable items in a supply chain when demand depends on both selling price and credit period," Computers and Industrial Engineering, vol. 57, no. 3, pp. 773-786, 2009.

[36] L. Chen and F. Kang, "Integrated inventory models considering the two-level trade credit policy and a price-negotiation scheme," European Journal of Operational Research, vol. 205, no. 1, pp. 47-58, 2010.

[37] J. Min, Y. Zhou, and J. Zhao, "An inventory model for deteriorating items under stock-dependent demand and two-level trade credit," Applied Mathematical Modelling, vol. 34, no. 11, pp. 3273-3285, 2010.

[38] C. H. Ho, "The optimal integrated inventory policy with price-and-credit-linked demand under two-level trade credit," Computers and Industrial Engineering, vol. 60, no. 1, pp. 117-126, 2011.

[39] T. L. Urban, "An extension of inventory models incorporating financing agreements with both suppliers and customers," Applied Mathematical Modelling, vol. 36, no. 12, pp. 6323-6330, 2012.

[40] K. J. Chung and L. E. Cardenas-Barron, "The simplified solution procedure for deteriorating items under stock-dependent demand and two-level trade credit in the supply chain management," Applied Mathematical Modelling, vol. 37, no. 7, pp. 46534660, 2013. 
[41] C. H. Su, L. Y. Ouyang, C. H. Ho, and C. T. Chang, "Retailer's inventory policy and supplier's delivery policy under twolevel trade credit strategy," Asia-Pacific Journal of Operational Research, vol. 24, no. 5, pp. 117-126, 2007.

[42] C. K. Jaggi, S. K. Goyal, and S. K. Goel, "Retailer's optimal replenishment decisions with credit-linked demand under permissible delay in payments," European Journal of Operational Research, vol. 190, no. 1, pp. 130-135, 2008. 


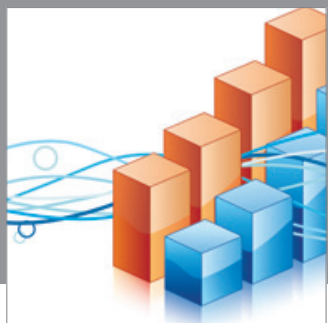

Advances in

Operations Research

mansans

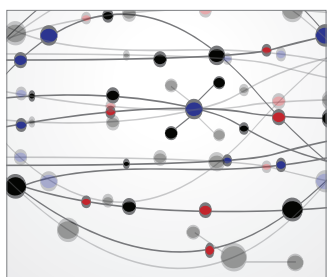

The Scientific World Journal
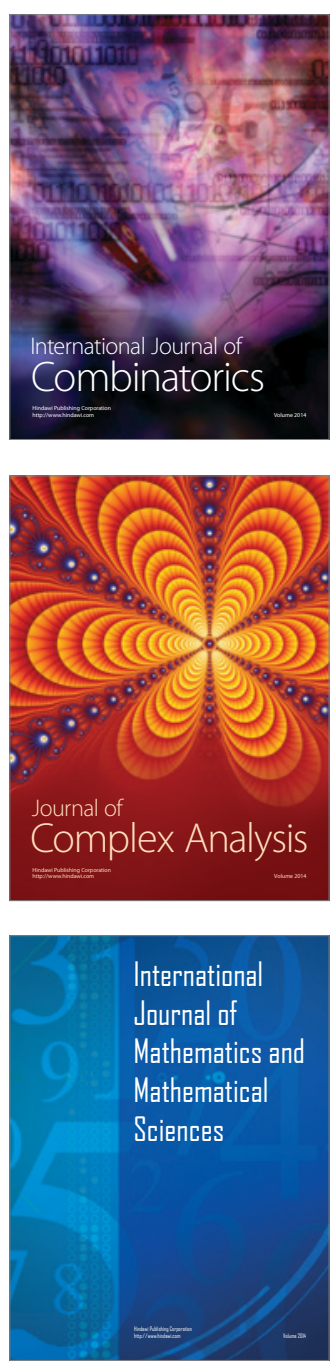
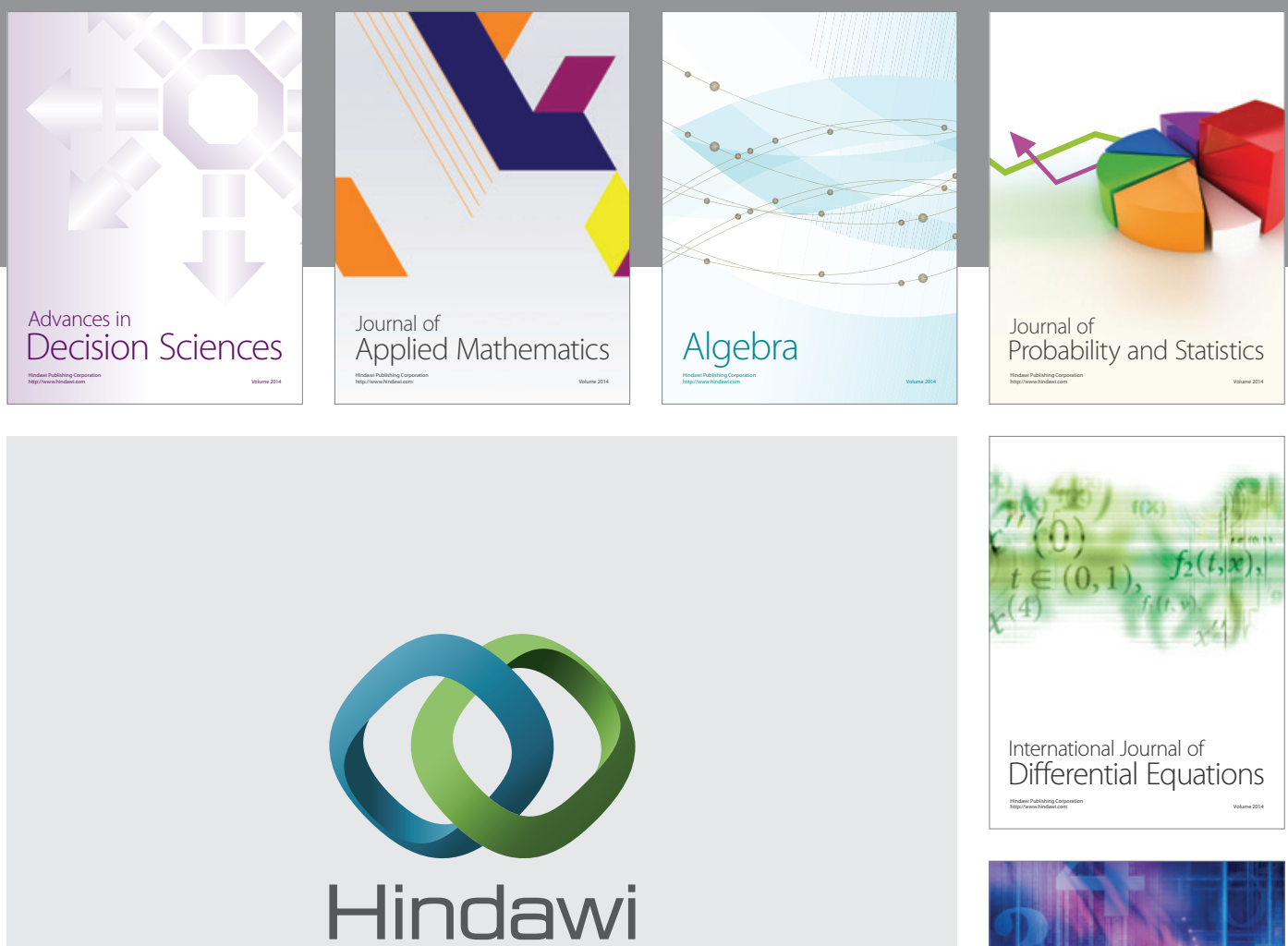

Submit your manuscripts at http://www.hindawi.com
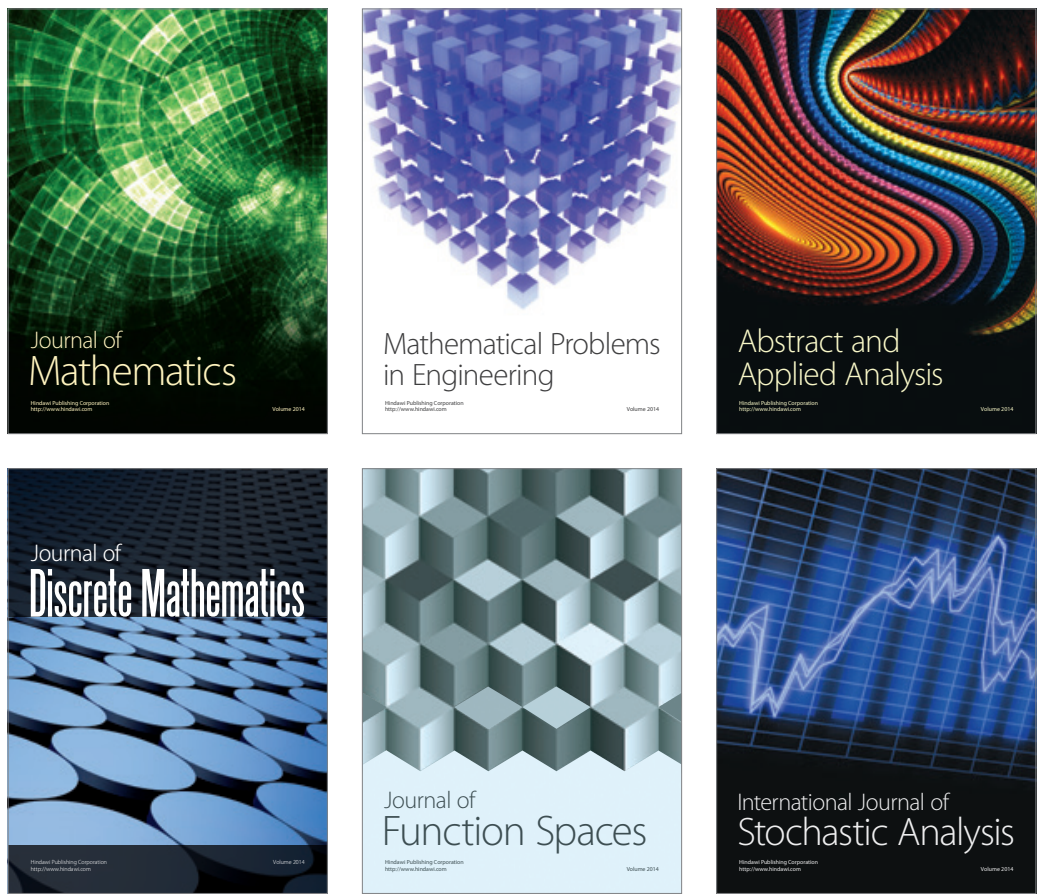

Journal of

Function Spaces

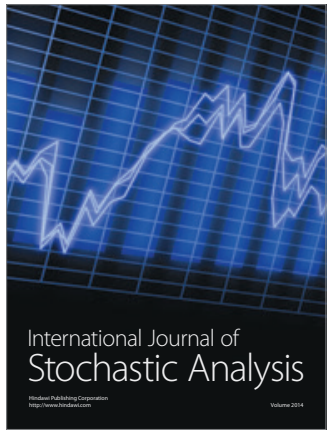

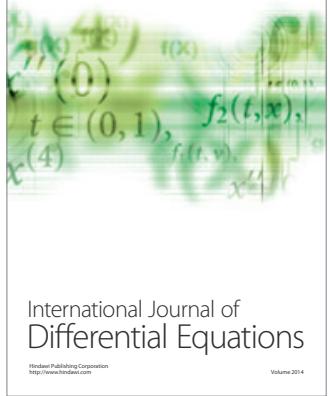
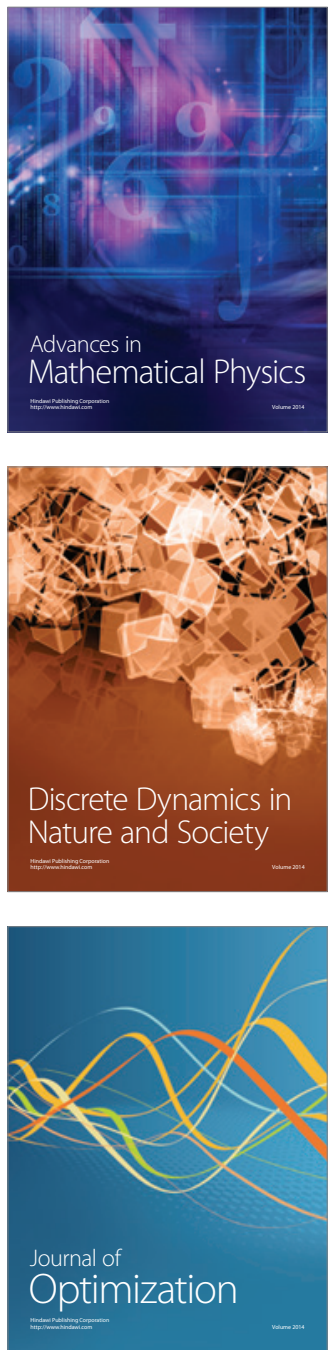